
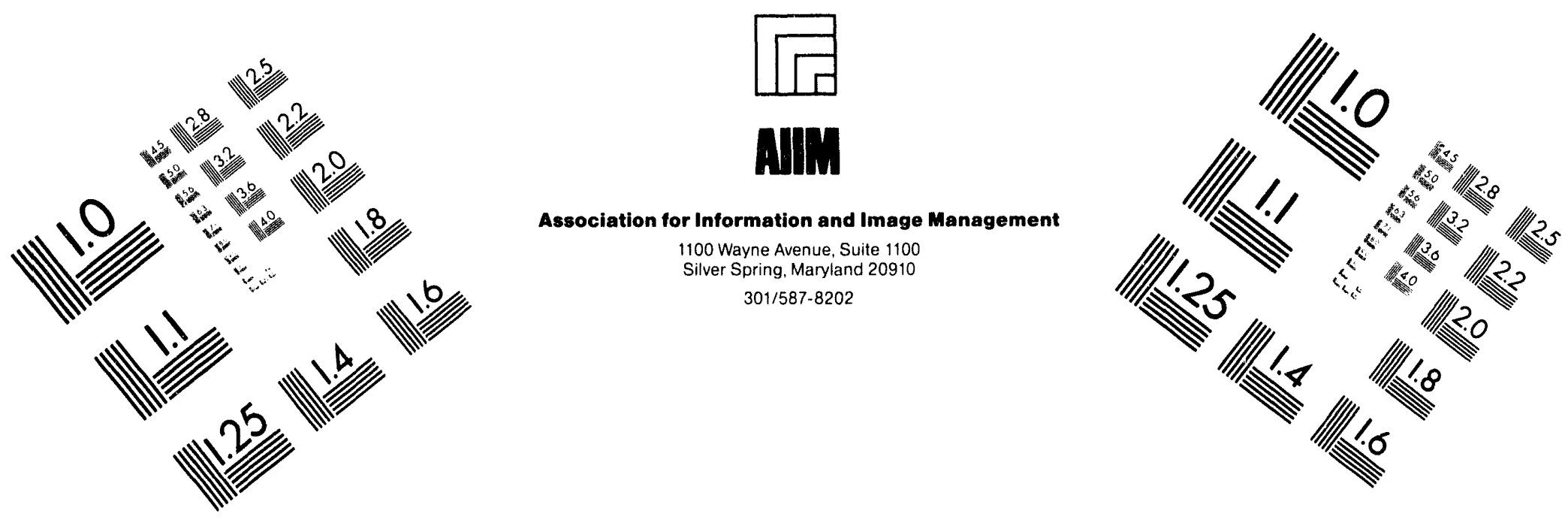

\title{
Centimeter
}

$\begin{array}{llllllllllllllll}1 & 2 & 3 & 4 & 5 & 6 & 7 & 8 & 9 & 10 & 11 & 12 & 13 & 14 & 15 & \mathrm{~mm}\end{array}$ $\mid$ Inches
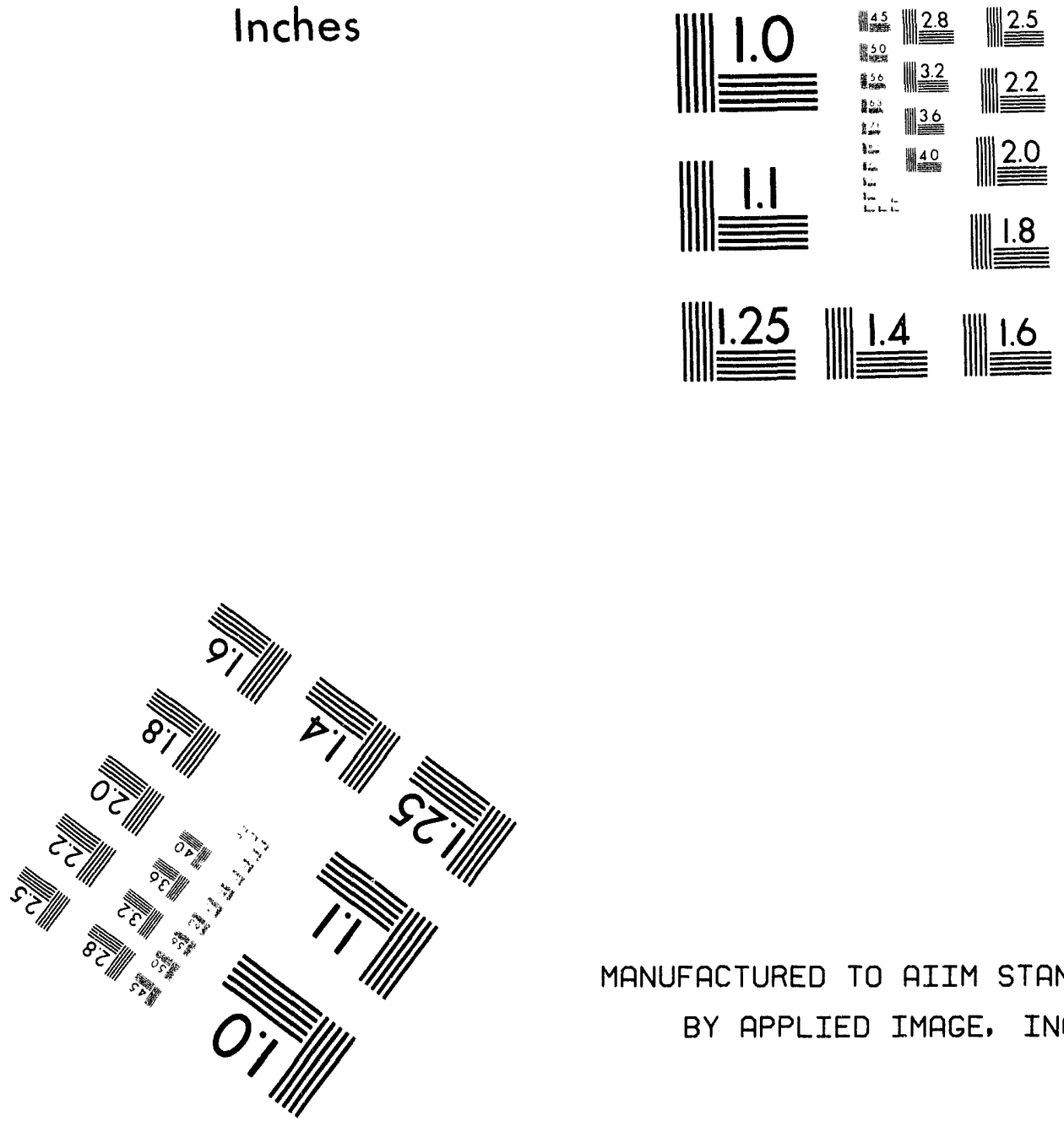

MANUFACTURED TO AIIM STANDARDS

BY APPLIED IMAGE, INC.

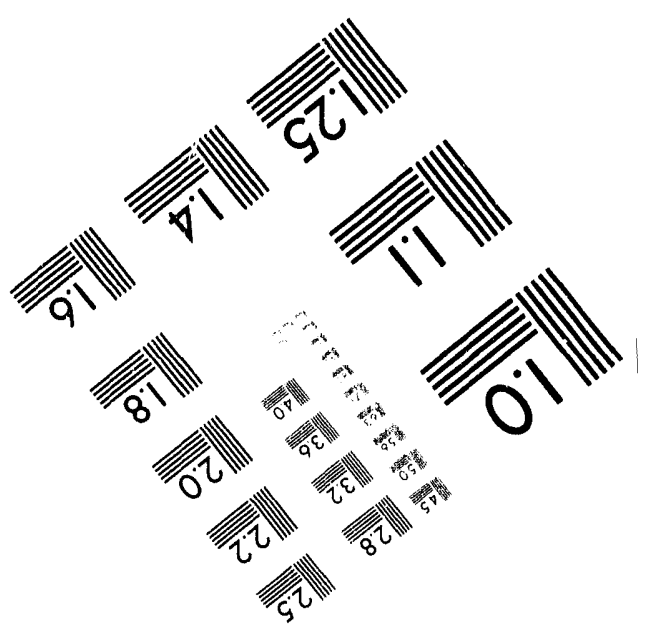



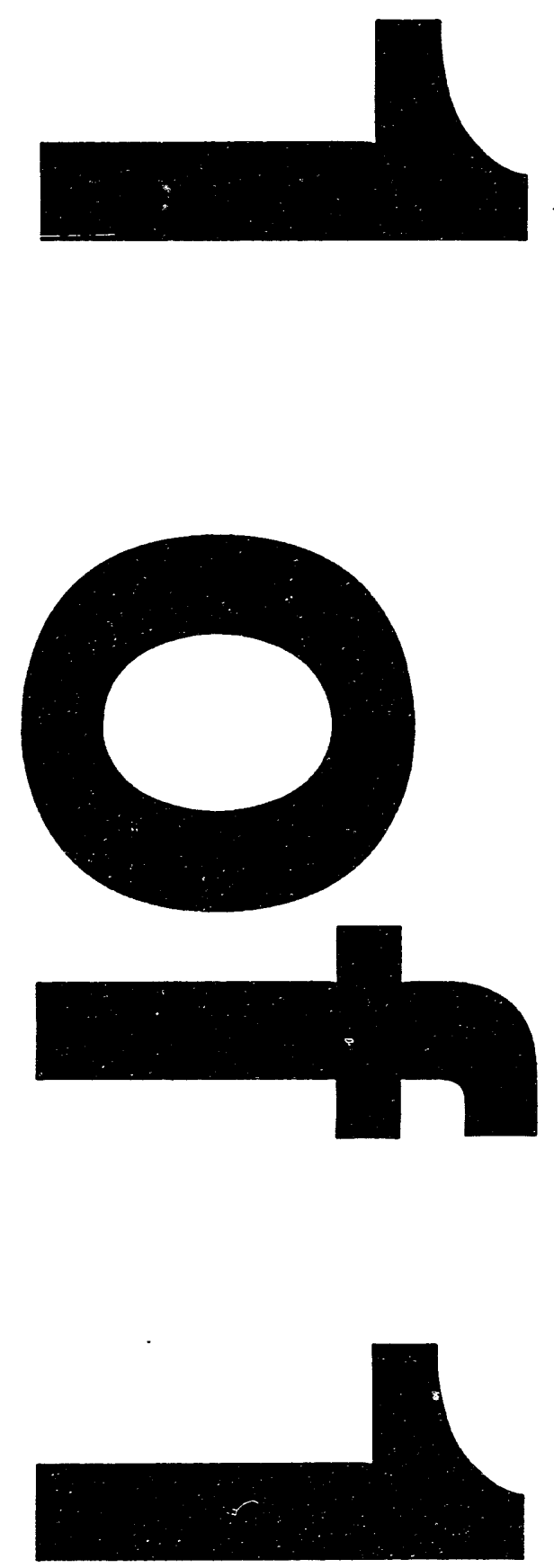
Date:

Report Period:

Project Number:

Project Title:

DOE Program Manager:

Principal Investigators:

Contractor:

Report Prepared by:
March 8, 1994

January 1, 1993 - December 31, 1993

DE-AC22-92MT92008

Development of a Cost Effective Environment

Compliance Technology for Stripper Brine Wells

Mr. Gene Pauling

Michael A. Adewumi and Robert W. Watson

202 Hosler Building

Petroleum and Natural Gas Section

The Pennsylvania State University

University Park, Pennsylvania 16802-5000

The Pennsylvania State University

Office of Sponsored Programs

118 Barbara Building II

University Park, Pennsylvania 16802

M.A. Adewumi, R.W. Watson, S. Tian, S. Heckman, S. Safargar, I. Drielinger

\section{OVERALL PROJECT OBJECTIVES}

The specific objective of the research is to demonstrate that the characteristics of wastewater from stripper oil wells and marginal gas wells are sufficiently similar to be treated under a standardized treatment methodology, that the environmental impacts of the discharge of treated brines from both stripper oil and marginal gas wells can be adequately regulated, and that the inclusion of marginal gas wells in the same category as stripper oil wells is appropriate, especially for wells operating in the Appalachian Basin.

\section{WORK PERFORMED DURING THE PREVIOUS YEAR (1992) U?}

The work accomplished during 1992 for both the field-scale and the laboratory-scale treatment facilities focused on iron removal from the field and synthetic brines. The laboratory work also included single-element kinetics studies to determine the effect of one metal on another with respect to the rates of the various reactions. The laboratory process studies investigated such 


\section{DISCLAIMER}

This report was prepared as an account of work sponsored by an agency of the United States Government. Neither the United States Government nor any agency thereof, nor any of their employees, makes any warranty, express or implied, or assumes any legal liability or responsibility for the accuracy, completeness, or usefulness of any information, apparatus, product, or process disclosed, or represents that its use would not infringe privately owned rights. Reference herein to any specific commercial product, process, or service by trade name, trademark, manufacturer, or otherwise does not necessarily constitute or imply its endorsement, recommendation, or favoring by the United States Government or any agency thereof. The views and opinions of authors expressed herein do not necessarily state or reflect those of the United States Government or any agency thereof. 
parameters as the sand bed thickness, the temperature of the system, the angle of the aeration unit, and the presence of the retention tank. All of these laboratory parametric studies provided insight into how each component of the treatment process contributes to the removal of iron from the synthetic brine. Similar studies have begun for investigating copper removal effectiveness. As for the field work, several brines from sandstone formations in Pennsylvania, such as the Red Valley brine and the Warren brine, were treated with the field unit. The results of our analyses indicated that the field unit effectively removes iron from these field brines.

\section{WORK PERFORMED DURING 1993}

\section{Kinetics Studies}

The kinetics studies consist of three parts, namely, critical pH studies, single element kinetics and multi-element kinetics. The single element kinetics of lead, zinc, copper, and aluminum and the catalytic effects of these elements on one another were investigated. The goal of these studies was to enhance our kinetics database, determine reaction rate constants, and incorporate this information into the design software. Some initial discrepancies in the raw data for determining rate constants were resolved, and the reaction rate constants have been incorporated into the design software.

Critical pH Studies. Initial runs determined the pH range where each metal under study began to react. These studies helped limit the scope and number of experiments by placing bounds on the $\mathrm{pH}$. First, the region of the $\mathrm{pH}$ scale where reactions took place was determined. The critical pH studies decreased the number of experiments that would have to be conducted in future studies by giving guidelines as to what $\mathrm{pH}$ values to use in future studies.

Each experiment required four liters of the synthetic brine. The temperature of the brine was held constant by a water jacket that was connected to a Neslab temperature control system. This was a necessity, since temperature can significantly affect the results of the kinetics studies. Synthetic brine was continuously aerated to ensure maximum air saturation and adequate mixing throughout the four liters of brine. The $\mathrm{pH}$ of the brine was continuously monitored with a Fisher Scientific digital pH meter equipped with a reverse-sleeve junction reference electrode and a 
temperature compensation probe. The $\mathrm{pH}$ probes required special consideration as the mixtures under study can easily plug standard probe membranes.

Metal stock solutions were prepared by dissolving the metal required in an acid solution and diluting to the required concentration for experimental use. The stock solutions were kept at a very low $\mathrm{pH}$ to maintain stable ion concentration. $2000 \mathrm{ppm}$ stock solutions were added to the brine to produce a solution of brine containing $50 \mathrm{ppm}$ of the metal under study.

Since the prepared stcck solutions contained rather high acid concentrations, the $\mathrm{pH}$ of the brine solution was very low, hence preventing any reaction. The $\mathrm{pH}$ of the solution was raised by the addition of small amounts of concentrated sodium hydroxide to the solution to adjust the pH value. As the $\mathrm{pH}$ gradually increased, $13 \mathrm{ml}$ samples were collected, filtered through 0.45 micron nylon syringe filters, and acidified by adding $1 \%$ by volume of concentrated hydrochloric acid to preserve them for later analysis. Each experiment is stopped when the $\mathrm{pH}$ reached a value of 10.0 .

Figures 1 through 4 show the critical $\mathrm{pH}$ data for each of the elements of interest. Figures 1 and 2 show that the critical $\mathrm{pH}$ values for aluminum and copper are 4.8 and 5.5, respectively. Figures 3 and 4 show that lead and zinc exhibit somewhat different behavior. The critical $\mathrm{pH}$ for these two elements is somewhat higher, 7.1 and 7.3. These data have been summarized in Table 1 .

Single-Element Kinetics. After defining the working $\mathrm{pH}$ region, kinetics experiments were conducted to determine the rate and order of reaction for each element under study in an isolated setting. By determining how the element reacted in the brine with no other elements present, a base number could be established.

As described previously, the metal under study was added to four liters of brine to produce a concentration of $50 \mathrm{ppm}$. The brine was continuously aerated and $\mathrm{pH}$ was monitored continuously. For these experiments the $\mathrm{pH}$ was adjusted directly to a desired value, somewhere near the critical $\mathrm{pH}$ valued determined from the previous study. The brine was then allowed to react for one hour. During this time, samples were collected, filtered and preserved with hydrochloric acid for later analysis. These experiments allowed the decrease in concertration of the metal of interest to be monitored under the given set of conditions (metal concentration, initial brine $\mathrm{pH}$, temperature, etc.). 
Figures 5 and 6 show examples of raw data for determining reaction rates as collected and plotted for copper and lead, respectively. This information is not yet useful but must first be modified to generate information for the model. Figures and 8 show typical modified plots from which the modeling data is extracted. The reaction data for single-element kinetics for copper, lead, aluminum and zinc have been obtained.

Multi-element kinetics. After collected base data on each of the metals, the experimental focus was broadened to include cumbinations of metals in solution. The main objective of this phase of the experimental work was to map out interactions between the elements. If an element such as copper was combined in solution with another element, e.g., aluminum, and a more rapid removal of aluminum was observed while the copper concentration remained constant in the solution, a catalytic effect was observed. If, on the other hand, removal rates of aluminum decreased, then an inhibitory effect was noted. This type of data is needed to supplement the single element kinetics information collected earlier to characterize the individual behavior of each element under consideration.

The laboratory procedure for multi-element kinetics was identical to that of the single element kinetics, except that the concentrations of the minor elements were also monitored for changes in concentration over time. Again, these data had to be manipulated and re-plotted in order to obtain useful information for the process modeling. Figures and show typical raw data obtained from these studies, while shows the finalized plot. The results of these studies are then used to modify the model to account for special occurrences as predicted by these experiments.

\section{Laboratory Scale Experiments}

A bench-scale model was constructed to test the effectiveness of the treatment process in removing dissolved elements from brine. The specific objectives of the laboratory evaluation were:

- To determine the treatment's efficacy under controlled conditions

- To refine the treatment process and to provide the data needed to complete the computer program 
- To verify the effectiveness of each component in the model

- To use the collected data for scale-up parameters.

Comprehensive laboratory evaluation on iron removal from synthetic brine was conducted during the past two years. The parametric studies for iron removal were completed. The general conclusions reached are summarized below.

- Increasing inlet iron concentration and flow rate decreases the efficiency of iron removal significantly.

- The first limestone column effects a significant increase in the $\mathrm{pH}$ value of the brine, while the addition of a second limestone column only has a slight positive effect on the treatment process.

- Increasing the angle of the aeration unit up to $45^{\circ}$ had a slight positive effect on the iron removal.

- Changes in the thickness of the sand bed in the filtration unit (from 2.5 to 5 inches) do not seem to have a significant effect on the iron removal.

- The retention tank is an essential component in the treatment process, as the tank provides sufficient time for the oxidation reaction to be completed.

- The temperature plays a significant role in the treatment process. Our studies indicated that lower temperature inhibited iron removal. In general, the temperature should be as great as possible (within reasonable limits) for effective iron removal.

A more detailed study was conducted on the sand filtration unit in order to determine approximately how often the sand must be replaced in the sand filtration unit. The laboratory treatment unit was operated over extended periods of time (144 hours), and sand cores were taken at several points within the sand filtration unit. The degree of sand "contamination" was observed as a function of time. The results of this study indicated that the life of the sand in the filtration unit is a function of flow rate and inlet iron concentration. In general, the sand in the filtration unit effectively filters out the heavy metals until the permeability of the sand is decreased to the point where the fluid begins to accumulate on the surface of the filtration unit. Figures 12 and 13 show the results of this study. 
An interesting observation that was made during this study was that the iron removed from the brine actually increased over time (see Figure 14). In other words, it would seem that the filtration unit became more effective at filtering iron over extended periods of time. A possible explanation of this phenomenon is that the iron precipitates gradually reduced the porosity and permeability of the sand, and the less permeable sand tended to have a higher filtration capacity. Of course, this effect is only valid until the point where the porosity and permeability are reduced so that water has accumulated on the surface of the filtration unit, at which time the sand must be replaced.

Upon completion of the laboratory process studies for iron removal, work began on investigating the effectiveness of copper removal from the synthetic brines. The preliminary results of these studies are encouraging, as the laboratory-scale unit seems to effectively remove copper from the synthetic brines. Figures 15-20 show that the copper concentration does decrease as the brine passes through the laboratory unit at various flow rates and angles of inclination of the aeration unit. The same parametric studies that were conducted for the iron will be conducted for determining copper removal effectiveness.

\section{Field Experiments}

During 1993, field tests were completed on the Cooper, Kane, and Bradford Sand brines at the field unit in Franklin, Pennsylvania. The field experiments were conducted year-round and under various weather conditions. The temperature at which the brines were treated was between 25 and $86^{\circ} \mathrm{F}$. Efforts to treat the brine at temperatures below $25^{\circ} \mathrm{F}$ failed because of the brine's freezing when passing through the aeration unit. Originally, the capacity of this field pilot model was designed for treating brine flowing at a rate of $1 \mathrm{bbl} / \mathrm{D}$. However, in order to determine the effect of the flow rate on the efficiency of the treatment, the flow rate was increased to as high as $16.5 \mathrm{bbl} / \mathrm{D}$. The experimental results obtained in this part of the field work further confirmed our previous conclusions that the field unit can effectively remove iron from the field brine under various weather conditions. Needless to say, there are some factors which affect the efficiency of the treatment process. These are discussed in the paragraphs that follow. 
Effect of Brine Flow Rate. The effect of the brine flow rate could be predicted even without any experimental work by considering the thin film flowing through the aeration unit. Since the size of the aeration unit is fixed, the thickness of the brine film over the aeration unit wil! increase as the flow rate increases. The contact between oxygen in the air and the iron ion in the brine will be minimized with a thicker film, and hence the efficiency of the treatment will be reduced. Tables 2 and 3 summarize the test results for Cooper brine and Bradford Sand brine, respectively. As the data in the tables show, at the same range of temperature, the efficiency of iron removal decreases slightly as flow rate increases. The average concentration of iron in Cooper brine is about $13 \mathrm{ppm}$. As Table 2 indicates, the iron concentration after the treatment is reduced below $3 \mathrm{ppm}$ under all the conditions tested. For the Bradford Sand brine, the iron concentration is reduced below $2 \mathrm{ppm}$ (see Table 3).

The effect of flow rate on brine treatment were also investigated for Kane brine. However, because of the low iron concentration in the original brine (about $8 \mathrm{ppm}$ ), almost all the iron is removed from the brine under all the conditions tested and no effect of flow rate can be seen within the range of flow rates tested $(4.5-16.5 \mathrm{bbl} / \mathrm{D})$.

Effect of Temperature. The field experiments were conducted year-round under various weather conditions. From the test results, it seems that no effect on brine treatment would be seen by sunny or cloudy conditions. However, the results do indicate that the temperature does affect the treatment efficiency, with higher temperatures increasing the efficiency.

Table 2 summarizes the test results for Cooper brine. It shows that at higher temperatures, more iron can be removed from the brine at the same flow rate. While the data in Table 2 are the statistical results from more than 150 samples taken from the field experiments, Figure 21 shows a specific example demonstrating the effect of temperature. This particular run began at noon and ended at 9:00 p.m. Of course, the temperature changed throughout the day. The curve in Figure 21 shows that iron concentration at the outlet end of the system increases as the temperature continuously decreases with time. This is an example of a wide range of temperature variation during one continuous run. For most other field tests, the temperature did not change as dramatically, and the efficiency of the treatment process is quite stable within one run. 
Experiments with Bradford Sand brine were conducted between April 7, 1993, and May 20, 1993. The temperature variation during these tests was not significant; therefore, no conclusion can be made as to the effect of temperature on the treatment of Bradford Sand brine.

As for the Kane brine, because of its low iron concentration, the effect of temperature is not obvious, either. The experimental results show that at temperatures above $32^{\circ} \mathrm{F}$ and flow rates between 4.5 and $6.5 \mathrm{bbl} / \mathrm{D}$, the iron concentration after treatment is reduced below $0.5 \mathrm{ppm}$. The only exception to this was seen in a test conducted when the temperature dropped below the freezing point while the system was running at a flow rate of $12 \mathrm{bbl} / \mathrm{d}$. In the case, the average iron concentration after treatment was $0.94 \mathrm{ppm}$.

Analysis for Organics. In addition, these field brines were tested for organics removal. The results from the organics analysis show that the brine treatment process can also remove a good percentage of various organics from the brine. Tables 4 and 5 show the typical results for organics removal from the field brines. A confirmation of the organics analysis is shown in Table 6, and two raw chromatograms are given in Figures 22 and 23. It can be seen in the tables that the field treatment process dramatically reduces organics content in the field brines.

With the arrival of winter weather during the last quarter of 1993, the field work was halted because of frigid conditions.

In the latter part of 1993 it was conceived to construct a mobile brine treatment facility. The obvious advantage of such a unit would be ease in transporting the unit from well-site to well-site. The design of this unit is underway and construction will begin in 1994.

Mobile Brine Treatment Facility. With the arrival of winter weather during the last quarter of 1993, the field work was halted because of frigid conditions. During this period, a new idea of constructing a mobile brine treatment facility was conceived. The obvious advantage of such a unit would be ease in transporting the unit from well-site to well-site and it will increase the flexibility and efficiency in conducting field work. There would be no need to transport the field brines from remote locations to the treatment site. The mobile unit could simply be driven to the well-site or to brine storage locations. 
A schematic diagram of the proposed mobile brine treatment is shown in Figure 24. All the components of the facility will be mounted on a $5 \times 8$-foot trailer. The size and location of each component are designed to conserve space The shaded units in the figure are "stacked" below the other units for this purpose. A generator is used to provide the power to a pump that draws the brine from the storage tank on the field into a 5-gallon separator. From this separator, the brine enters the pH-adjustment unit, which consists of four limestone columns, each being 4 inches in diameter and 4 feet tall. These columns will be plumbed in such a way that they can be used individually or in any combination with each other. Fluid from the $\mathrm{pH}$ adjustment unit is directed to the aeration unit. This unit is designed with an adjustable angle to effect the desired brine film thickness. The proposed size of this unit is 1.5 feet wide, 3 inches deep, and 3 feet long. The aerated brine then enters the retention tank, which is 2.5 feet long, 1.5 feet high, and 1.5 feet wide. The brine is then directed into the sand filtration unit, located directly below the retention tank. The filtration unit will be 2 feet in length and 1.5 feet in height. With the treatment process complete, the brine is held in a five-gallon accumulation tank. When a certain volume of brine is collected in the accumulation tank, an automatic switch will turn on a second pump which transfers the treated brine to two 30-gallon storage units, for a total storage capacity of 60 gallons. When the operation is complete, the second pump will discharge the treated brine back to the field $\operatorname{tank}(\mathrm{s})$. Various sampling ports will be constructed throughout the treatment process. Samples will be collected and shipped to Penn State for analysis and evaluation.

\section{Development of Design Software}

A DOS-based, user-friendly software for brine treatment facility design has been developed. This software can be used for parametric study as well as for system design purposes. At this stage, the calculations performed by the software are based only on iron removal from brine. However, this will serve as the basis for the development of a comprehensive software package that can handle the removal of other undesirable elements in the brine. Tests were conducted to ensure that the software is bug-free. A user's manual has been developed, and has been sent with the software to several operators and the Pennsylvania Department of Environmental Resources (DER) for their use and evaluation. The following discusses some examples of using this software. 
The design of the brine treatment facility consists of all the individual units. However, the most important part of the brine treatment facility is the aeration unit. It is the place where the thin film of brine is created and the oxidation reaction takes place. The length, width and the angle of inclination of the aeration unit all affect the efficiency of the brine treatment. Therefore, the design of the aeration unit must consider all these three parameters.

Length of Aeration Unit. The length of the aeration unit is the distance that brine flow in thin film. This distance should provide sufficient contact time between air and the iron in the brine. The thinner the brine film, the less contact time is needed. Therefore, the length of the aeration unit depends not only on the iron concentration of the brine but also the flow rate and the width of the aeration unit. Figures 25 through 27 show examples of the design of the length of the aeration unit. In Figure 25, the iron concentration of the brine is $50 \mathrm{ppm}$; the rate needs to be treated is $0.5 \mathrm{gal} / \mathrm{min}$ and the operating temperature is set to be $60^{\circ} \mathrm{F}$. Two curves are drawn in the figure, for the width of aeration unit of $2 \mathrm{ft}$. and $4 \mathrm{ft}$., respectively. The angle of the aeration unit is $15^{\circ}$ for both cases. As the outlet iron concentration decreases, the required length of aeration unit increases. However, as indicated in the figure, the relation is not linear. Furthermore, it can be observed from Figures 8.1 to 8.3 that by doubling the width of aeration unit (from $2 \mathrm{ft}$. to $4 \mathrm{ft}$.), the required length of the aeration unit does not necessarily decrease by half. Figure 26 is the plot of length of aeration unit vs. inlet iron concentration. At a fixed flow rate, outlet iron concentration, temperature and the angle of aeration unit, the required length increases as the inlet iron concentration increases. However, the increase is much more rapid for an aeration unit with a width of $2 \mathrm{ft}$. than for one that is $4 \mathrm{ft}$. wide. The reason for this is that a narrower aeration unit will tend to have a thicker brine film. For high inlet iron concentrations, ample contact between the air and the iron must occur. Hence, the thicker film requires a longer length to provide the necessary contact time. Figure 27 shows the relation between the length of the aeration unit and the flow rate. When all other parameters are fixed, a longer aeration unit is needed at a higher flow rate. Again, the relation is not linear, even though the curves in the figure appear to be straight lines.

Width of Aeration Unit. In practice, the maximum length of the aeration unit could be limited by the available space. If the length of aeration unit called for by the design is too long, one may specify a length which seems feasible and attempt to design the width. At a constant flow rate, a wider aeration unit will produce a thinner film over the unit. This, in turn, will create a 
better contact between the oxygen in the air and the iron in the brine. Figure 28 shows the relation between the width of the aeration unit and the outlet iron concentration while all the other variables are fixed. The shape of the curves in Figure 28 is very similar to that in Figure 25. It is understandable since both length and width affect the area of the aeration unit. It can be observed in the two figures that doubling the width of the aeration unit reduces the required length by more than half (Figure 25), while doubling the length of aeration unit decreases the necessary width by less than half (Figure 28), even though the relationship between the length and width and the area of the unit remains constant. Figure 29 shows the width of aeration unit as a function of inlet iron concentration. As shown in the figure, the required width of the aeration unit increases with inlet iron concentration when all the other parameters are fixed. However, the rate of increase varies. If the inlet iron is set equal to the outlet iron concentration, the width of the aeration unit should be zero, since no treatment is needed. As the value of inlet iron concentration increases from the outlet iron concentration, the required width of the aeration unit increases sharply. However, the rate of increase in width moderates when the value of inlet iron concentration surpasses $20 \mathrm{ppm}$. This indicates that the required width of aeration unit is not designed based on a simple proportion to the inlet iron concentration. The relation between the width of the aeration unit and the flow rate is linear. This is understandable since the brine flow is evenly distributed over the aeration unit. A proportional increase in the flow rate and the width of the aeration unit would not change the thickness of the brine film; hence, it would not affect the reaction between oxygen in air and iron in brine.

Angle of Aeration Unit. The effect of the angle of inclination of the aeration unit is twofold, since the oxidation reaction between oxygen and iron is affected by the contact area as well as the contact time. As the angle of the aeration unit is increased, the thickness of brine film decreases, thus increasing the contact area and improving treatment effectiveness. At the same time, an increased angle will increase the flow rate of the brine, thus reducing the contact time between oxygen and iron. This effect hinders treatment effectiveness. Hence, an optimum angle of aeration unit exists where a balance is achieved between these two opposing effects.

Perhaps the best way to determine the optimum angle is to create a table similar to Tables 7 and 8 using the design software. The purpose of these tables is to determine lengths of the aeration unit at various widths and angles with the required flow rate and inlet and outlet 
concentrations. Such a table is particularly useful when one can construct the aeration unit at different sizes, so that one can select the combination of the length, width and angle which best suits one's needs. For example, from Table 8, one can find the following optimal combination of size and angle of aeration unit. If the width of the unit is 2 feet, one may set the angle between $25^{\circ}$ and $36^{\circ}$ (with a length of $7.4 \mathrm{feet}$ ). If the width is 3 feet, then a better range of angles would be between $16^{\circ}$ and $25^{\circ}$ (with a length of $5 \mathrm{feet}$ ). If the length and width are limited to less than 3 and 5 feet, respectively, from the table, one can observe that the angle has to be between $9^{\circ}$ and $16^{\circ}$.

Efficiency of Brine Treatment. The purpose of this calculation is to determine how much iron can be removed from a particular brine by the treatment process with an available aeration unit. Figure 30 shows one of the examples of outlet iron concentration calculation. Two different sizes ( $3 \times 2$ feet and $4 \times 3$ feet) of aeration units are considered. Both aeration units are inclined at $15^{\circ}$. The treatment is run at a temperature of $60^{\circ} \mathrm{F}$ and a flow rate of $0.5 \mathrm{gal} / \mathrm{min}$. The curves in the figure show the relation between the inlet and outlet iron concentrations. With the flow rate, size and angle fixed, the curves show that the outlet concentration increases with inlet concentration. When the inlet concentration is below $5 \mathrm{ppm}$, both sizes of aeration unit can essentially remove all the iron from the brine. However, as the inlet iron concentration increases, the larger size unit still removes most of the iron from the brine, while the efficiency of the smaller unit decreases rapidly. The area of the larger unit is only twice that of the smaller one. Nevertheless, the treatment efficiency of the two units remains disparate.

Maximum Inlet Iron Concentration. The purpose of calculating the maximum inlet iron concentration is to estimate the worst case that the facility can handle. However, the calculated maximum inlet iron concentration corresponds to a given flow rate. At a lower flow rate, a higher value could be obtained for the maximum inlet iron concentration with the same facility, while at higher flow rates, the maximum inlet iron concentration should be smaller.

Figure 31 shows a sample determination of the maximum inlet iron concentration. The two curves in the figure represent two different sizes of the aeration unit. The shape of the two curves is very similar in that each of the curves has two branches, one near vertical and one near horizontal. This indicates that there is a critical point which separates two distinct regions. In the first region (the vertical segment), the thickness of brine film in the aeration unit dominates the 
treatment process. As the flow rate (hence the film thickness) increases, the maximum iron concentration that the given aeration unit can handle decreases sharply. It is easy to understand that the larger unit should have a higher critical point, since at the same flow rate, the thickness of the film flowing through the larger unit is much less than that flowing through the smaller one. When the thickness of brine film is greater than the critical point (the horizontal branch), the thickness of the film does not have much effect on the treatment process. Hence the facility's capability of handling the maximum iron concentration does not change significantly with flow rate. Needless to say, the efficiency of the treatment is much lower in the latter case.

Maximum Flow Rate. Quite often one may need to determine the maximum flow rate an existing facility can handle and still remove iron effectively. Figure 32 illustrates a prediction of maximum flow rate. Again, two sizes of aeration units are considered. As indicated by the curves in the figure, the larger unit can handle almost twice the flow rate as the smaller one with the same inlet and outlet iron concentration. The maximum flow rate that a given aeration unit can handle increases gradually with the outlet iron concentration.

\section{WORK SCHEDULED FOR THE NEXT YEAR (1994)}

One of the primary tasks planned for this project in 1994 is to construct and test a mobile field treatment facility. We are excited about this unit and the resulting benefits of possessing a transportable unit. This mobile unit will make it possible for us to test more field brines right at the well-site and to introduce the brine treatment process directly to oil/gas producers. On other fronts, the multi-element kinetics analysis will be completed and results incorporated into the software. The laboratory process studies will continue with other heavy metals of interest. The results of these studies will enhance our kinetic and process database. The database will be analyzed and the multi-element reaction model will be developed. The design software will be extended to include the calculations of other heavy metals as well as the organics. We will continue to accept suggestions for improving the design software and user's manual. The software will be fine-tuned and improved in the area of user-friendliness. The result will be a comprehensive, brine treatment facility design software package. 
Table 1. Critical pH Values for Elements of Interest

\begin{tabular}{|c|c|}
\hline Element & Critical pH \\
\hline \hline Aluminum & 4.8 \\
\hline Copper & 5.5 \\
\hline Lead & 7.1 \\
\hline Zinc & 7.3 \\
\hline
\end{tabular}

Table 2. Effect of Temperature and Flow Rate on Brine Treatment for Cooper Brine (Iron Concentration after Treatment, ppm)

\begin{tabular}{|c|c|c|c|c|}
\hline \multirow{2}{*}{ Temperature $\left({ }^{\circ} \mathbf{F}\right)$} & \multicolumn{4}{|c|}{ Flow Rate (bbl/D) } \\
\cline { 2 - 5 } & 4.5 & 8.0 & 12.0 & 16.5 \\
\hline $32-50$ & $0.3-0.9$ & $0.8-2.0$ & $1.4-2.5$ & $2.0-3.0$ \\
\hline $50-55$ & $0.3-0.4$ & $0.4-0.7$ & $0.7-0.9$ & $1.0-1.7$ \\
\hline
\end{tabular}

Table 3. Effect of Flow Rate on Brine Treatment for Bradford Sand Brine

\begin{tabular}{|c|c|c|c|c|}
\hline \multirow{2}{*}{} & \multicolumn{4}{|c|}{ Flow Rate (bbl/D) } \\
\cline { 2 - 5 } & 4.5 & 8.0 & 12.0 & 16.5 \\
\hline \hline Inlet Iron Concentration (ppm) & 11.23 & 11.41 & 12.45 & 11.79 \\
\hline Outlet Iron Concentration (ppm) & 0.27 & 0.66 & 0.92 & 1.68 \\
\hline
\end{tabular}


Table 4. GC/MS Analysis for Organics in Cooper Brine

\begin{tabular}{|c|c|c|c|}
\hline Compound Name & Inlet Sample & Outlet Sample & Percentage Removed \\
\hline \hline 2-Pentanol, 2-methyl & 475 & 87 & $\mathbf{8 2}$ \\
\hline 3-pentanol, 3-methyl & 388 & 161 & $\mathbf{5 9}$ \\
\hline Toluene & 845 & 209 & $\mathbf{7 5}$ \\
\hline 2-hexanone & 206 & 66 & $\mathbf{6 8}$ \\
\hline 2-hexanol, 2-methyl & 560 & 184 & $\mathbf{6 7}$ \\
\hline 3-pentanol, 2,3-dimethyl & 320 & 124 & $\mathbf{6 1}$ \\
\hline benzene, dimethyl & 817 & 133 & $\mathbf{8 4}$ \\
\hline hexanol, dimethyl & 423 & 93 & $\mathbf{7 8}$ \\
\hline heptane, 4-methyl & 1577 & 647 & $\mathbf{5 9}$ \\
\hline nonane, branch & 505 & 157 & $\mathbf{6 9}$ \\
\hline nonane, branch & 243 & 80 & $\mathbf{6 7}$ \\
\hline octane, 4-methyl & 590 & 234 & $\mathbf{6 0}$ \\
\hline Total & $\mathbf{6 9 4 9}$ & $\mathbf{2 1 7 5}$ & $\mathbf{6 9}$ \\
\hline
\end{tabular}

Table 5. GC/MS Analysis for Organics in Kane Brine

\begin{tabular}{|c|c|c|c|}
\hline Compound Name & Inlet Sample & Outlet Sample & Percentage Removed \\
\hline \hline Toluene & 505 & 281 & 44 \\
\hline Xylene & 380 & 281 & $\mathbf{3 9}$ \\
\hline Octane, branch & 407 & 595 & $?$ \\
\hline $\mathrm{n}-\mathrm{C}_{12}$ & 266 & 0 & $\mathbf{1 0 0}$ \\
\hline $\mathrm{n}-\mathrm{C}_{13}$ & 445 & 0 & $\mathbf{1 0 0}$ \\
\hline $\mathrm{n}-\mathrm{C}_{14}$ & 818 & 98 & $\mathbf{8 8}$ \\
\hline $\mathrm{n}-\mathrm{C}_{15}$ & 1270 & 0 & $\mathbf{1 0 0}$ \\
\hline
\end{tabular}




\begin{tabular}{|c|c|c|c|}
\hline Compound Name & Inlet Sample & Outlet Sample & Percentage Removed \\
\hline $\mathrm{n}-\mathrm{C}_{16}$ & 1782 & 0 & 100 \\
\hline $\mathrm{n}-\mathrm{C}_{17}$ & 1680 & 0 & 100 \\
\hline $\mathrm{n}-\mathrm{C}_{18}$ & 1597 & 0 & 100 \\
\hline $\mathrm{n}-\mathrm{C}_{19}$ & 1251 & 0 & 100 \\
\hline $\mathrm{n}-\mathrm{C}_{20}$ & 972 & 0 & 100 \\
\hline $\mathrm{n}-\mathrm{C}_{21}$ & 544 & 0 & 100 \\
\hline $\mathrm{n}-\mathrm{C}_{22}$ & 282 & 0 & 100 \\
\hline Total & 12199 & 1205 & 90 \\
\hline
\end{tabular}

Table 6. Confirmation of GC/MS Analysis for Organics

\begin{tabular}{|c|c|c|c|}
\hline Compound Name & MS Area (Inlet) & GC Area (Inlet) & MS Area (Outlet) \\
\hline 2-Pentanol, 2-methyl & 475 & & 87 \\
\hline 3-pentanol, 3-methyl & 388 & & 161 \\
\hline Toluene & 845 & 343 & 209 \\
\hline 2-hexanol, 2-methyl & 560 & 231 & 184 \\
\hline 3-pentanol, 2,3-dimethyl & 320 & 131 & 124 \\
\hline benzene, dimethyl & 817 & 336 & 133 \\
\hline hexanol, dimethyl & 423 & 199 & 93 \\
\hline heptane, 4-methyl & 1577 & 615 & 647 \\
\hline nonane, branch & 505 & 197 & 157 \\
\hline nonane, branch & 243 & 80 & 96 \\
\hline octane, 4-methyl & 590 & 134 & 234 \\
\hline Total & 6743 & 2282 & 2109 \\
\hline
\end{tabular}




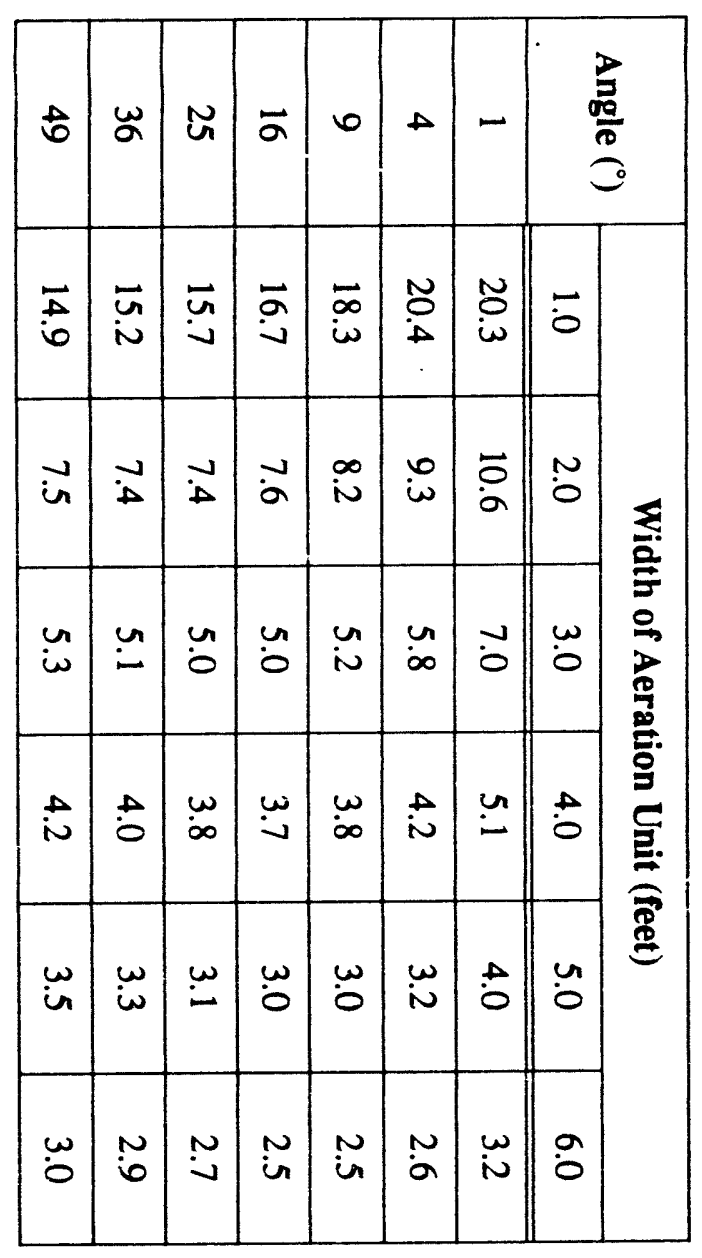

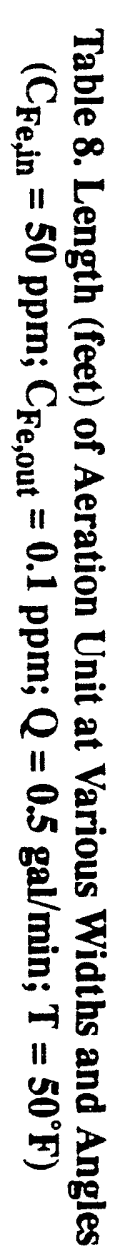

\begin{tabular}{|c|c|c|c|c|c|c|c|c|}
\hline $\overrightarrow{0}$ & 岁 & $\tilde{\omega}$ & $\bar{a}$ & 0 & $\rightarrow$ & - & 3 & $\frac{0}{0}$ \\
\hline$\vec{\omega}$ & $\vec{\omega}$ & $\overrightarrow{\dot{B}}$ & $\vec{u}$ & $\vec{a}$ & $\mid \begin{array}{l}\tilde{O} \\
0\end{array}$ & $\begin{array}{c}\tilde{i} \\
0\end{array}$ & $\dot{0}$ & \\
\hline$\ddot{0}$ & i & $\ddot{A}$ & $\hat{b}$ & $\vec{a}$ & $\because$ & $\begin{array}{l}\overrightarrow{0} \\
\end{array}$ & $\stackrel{N}{O}$ & $\sum$ \\
\hline $\overrightarrow{0}$ & $\stackrel{0}{0}$ & 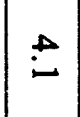 & $\vec{\omega}$ & $\stackrel{\vec{\sim}}{*}$ & $i n$ & $\hat{\theta}$ & 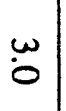 & $\frac{0}{2}$ \\
\hline$\stackrel{\omega}{0}$ & $\ddot{0}$ & $\ddot{0}$ & $\stackrel{\omega}{-}$ & $\begin{array}{l}\omega \\
\oplus\end{array}$ & $\begin{array}{c}\omega \\
0\end{array} \mid$ & $\dddot{n}$ & $\overrightarrow{0}$ & $\underline{\underline{E}}$ \\
\hline$\stackrel{N}{N}$ & $\stackrel{N}{\perp}$ & $\stackrel{N}{\wedge}$ & $\stackrel{N}{\Delta}$ & $\begin{array}{l}N \\
a\end{array}$ & $\mid \begin{array}{c}\ddot{0} \\
0\end{array}$ & $\underset{i}{w}$ & $\dddot{0}$ & \\
\hline סֶ & $\tilde{\sigma}$ & $\tilde{O}$ & $\tilde{O}$ & $N$ & $\begin{array}{l}n \\
\Delta\end{array}$ & $\omega$ & 8 & \\
\hline
\end{tabular}

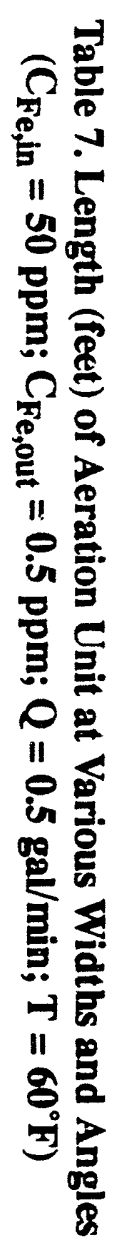



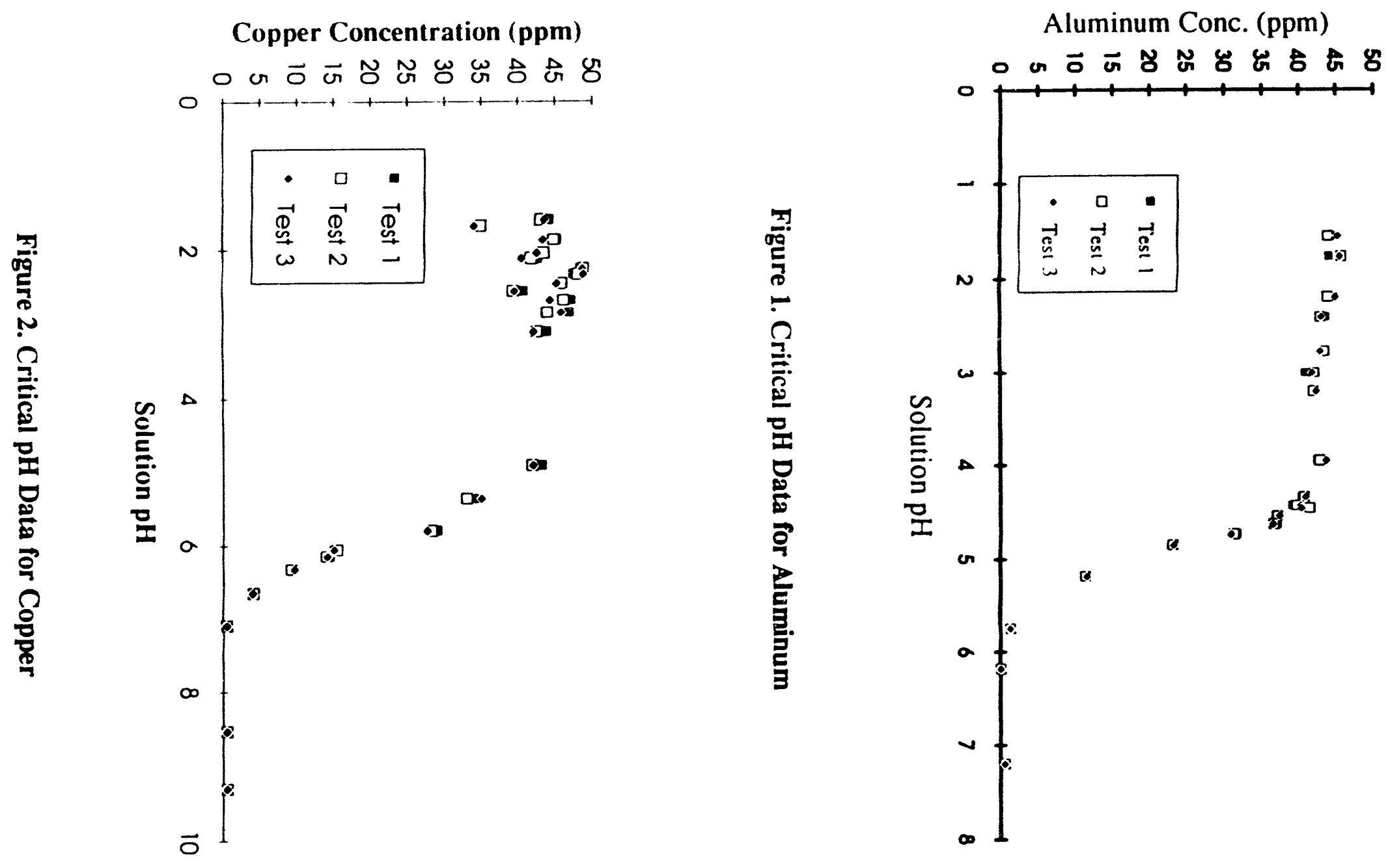


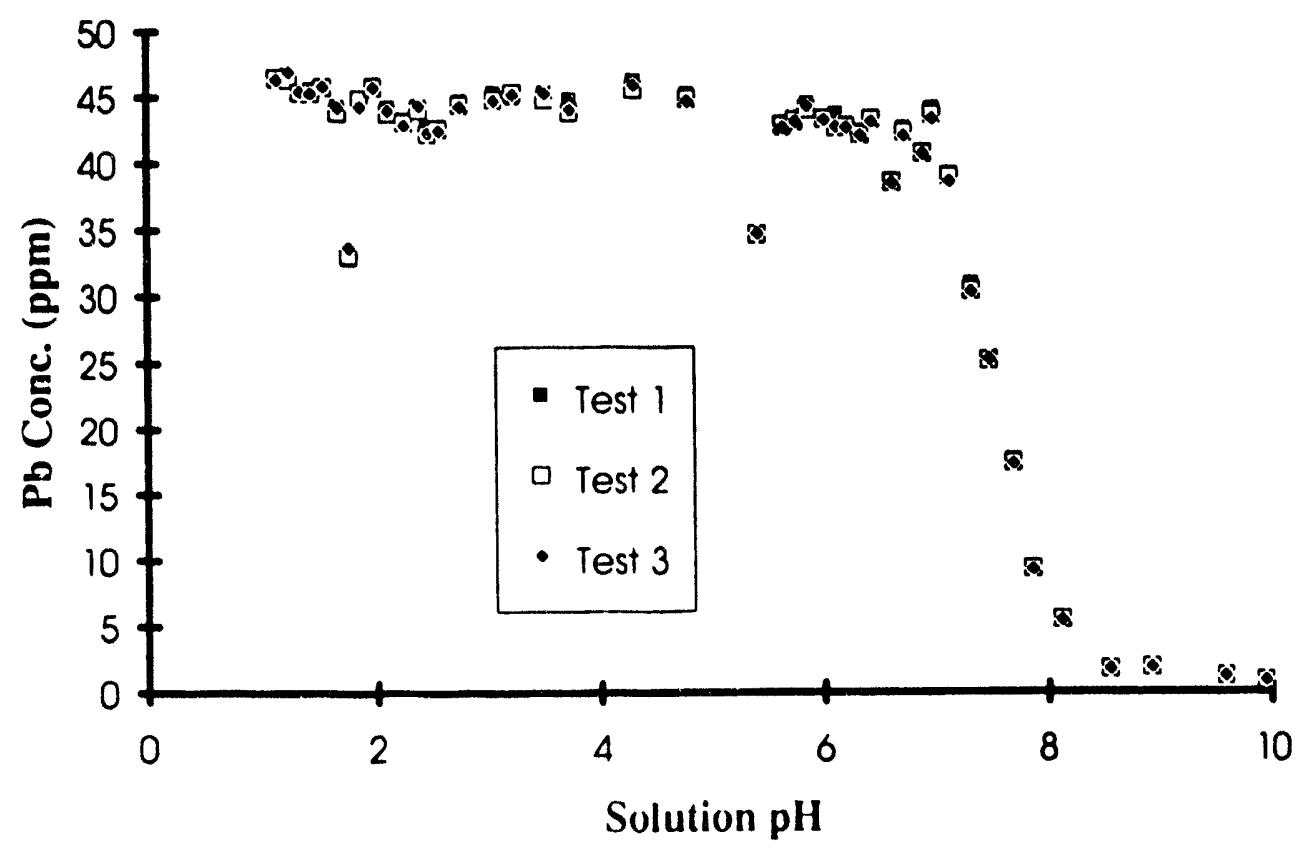

Figure 3. Critical pH Data for Lead

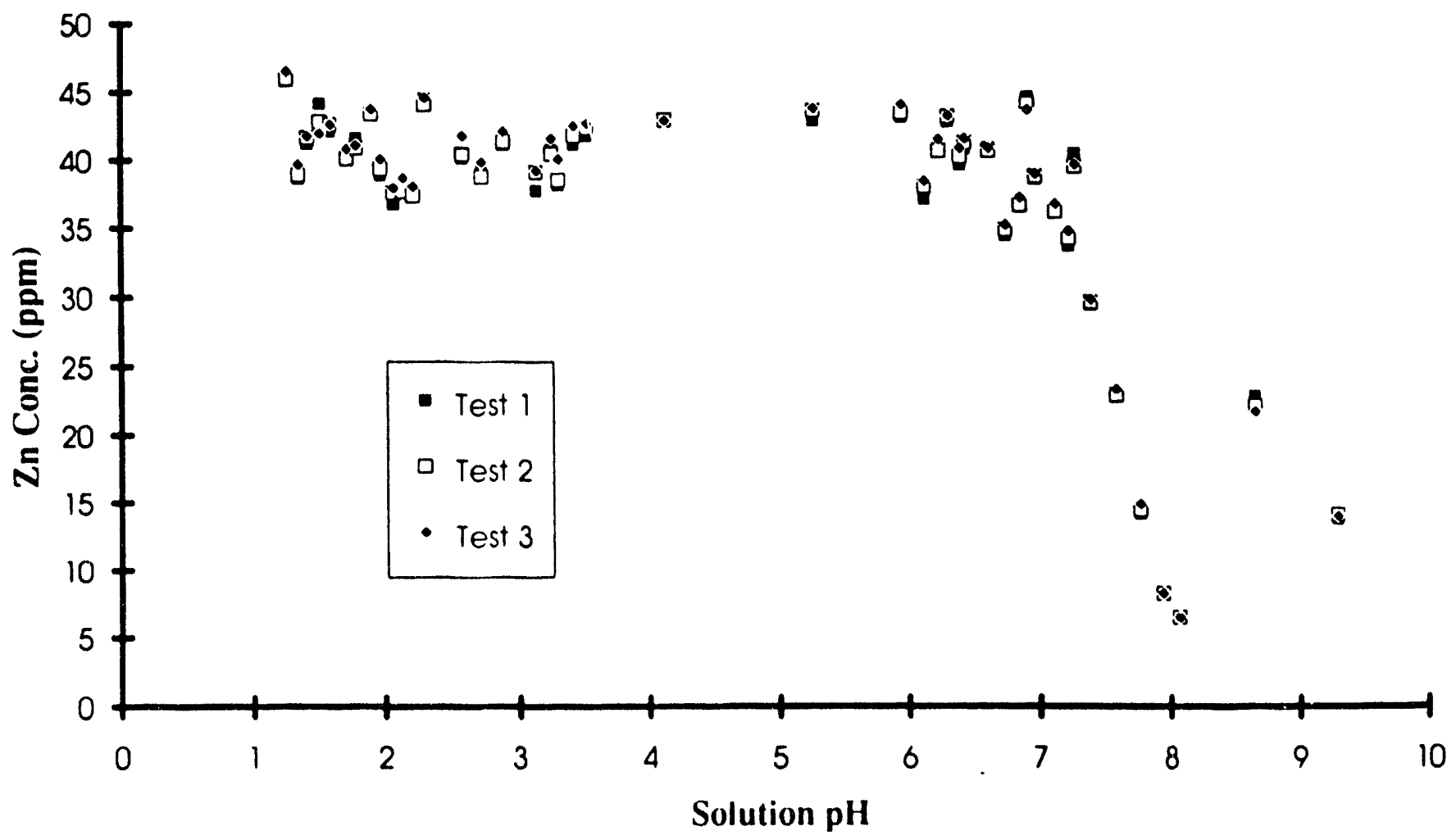

Figure 4. Critical pH Data for Zinc 


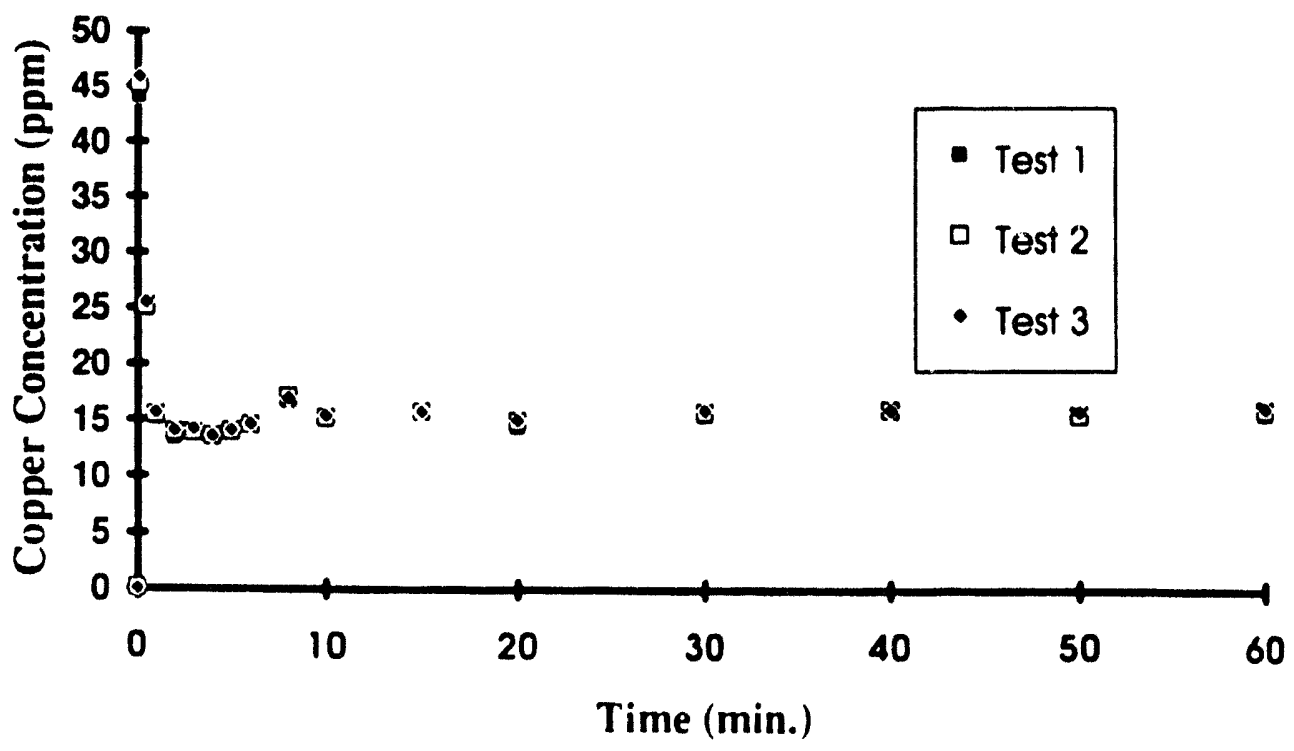

Figure 5. Raw Kinetics Data for Determining Reaction Rate for Copper

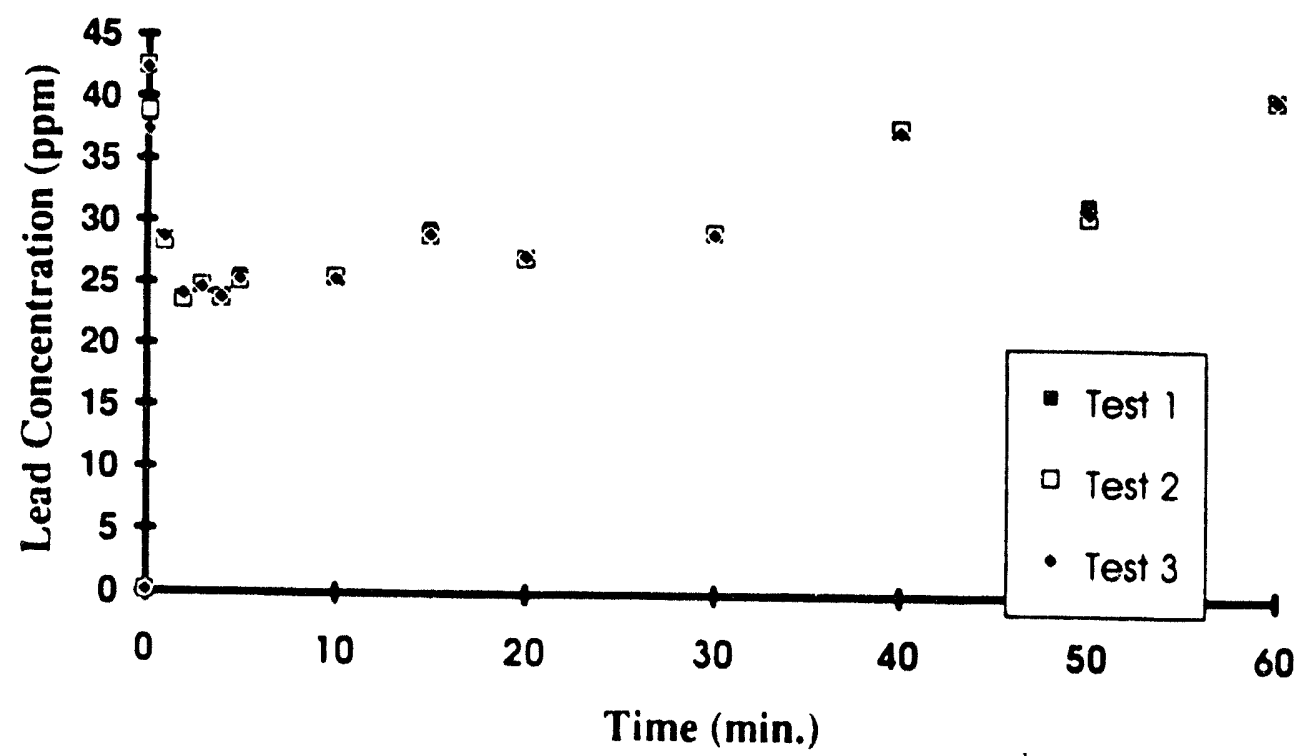

Figure 6. Raw Kinetics Data for Determining Reaction Rate for Lead 


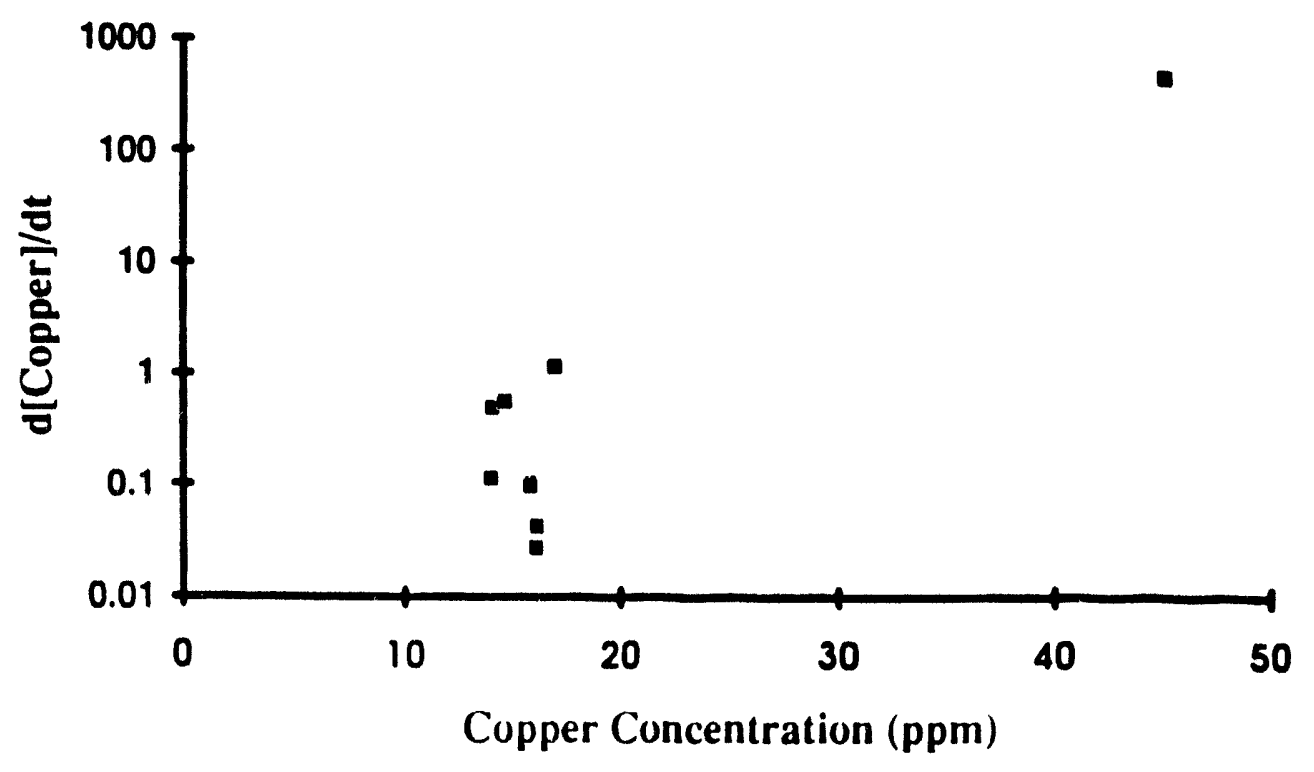

Figure 7. Modified Plot for Determining Reaction Rate for Copper

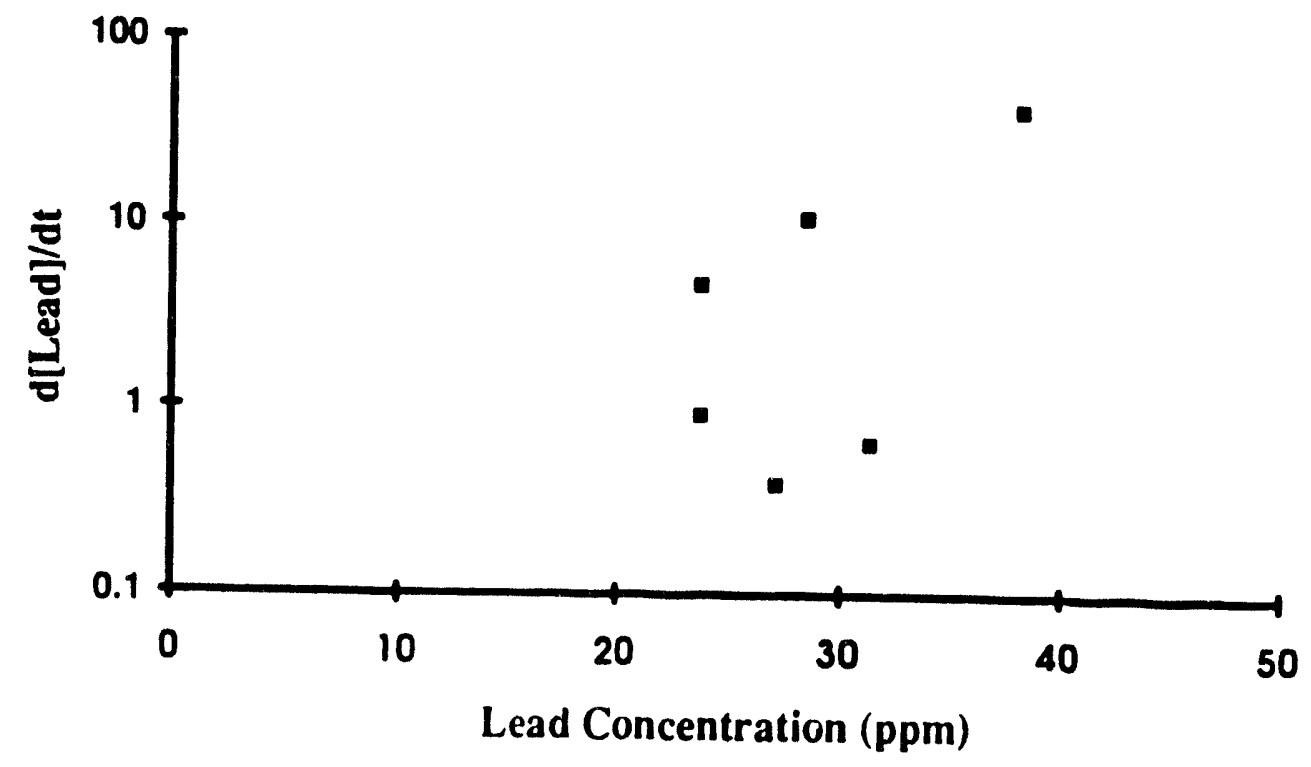

Figure 8. Modified Plot for Determining Reaction Rate for Lead 


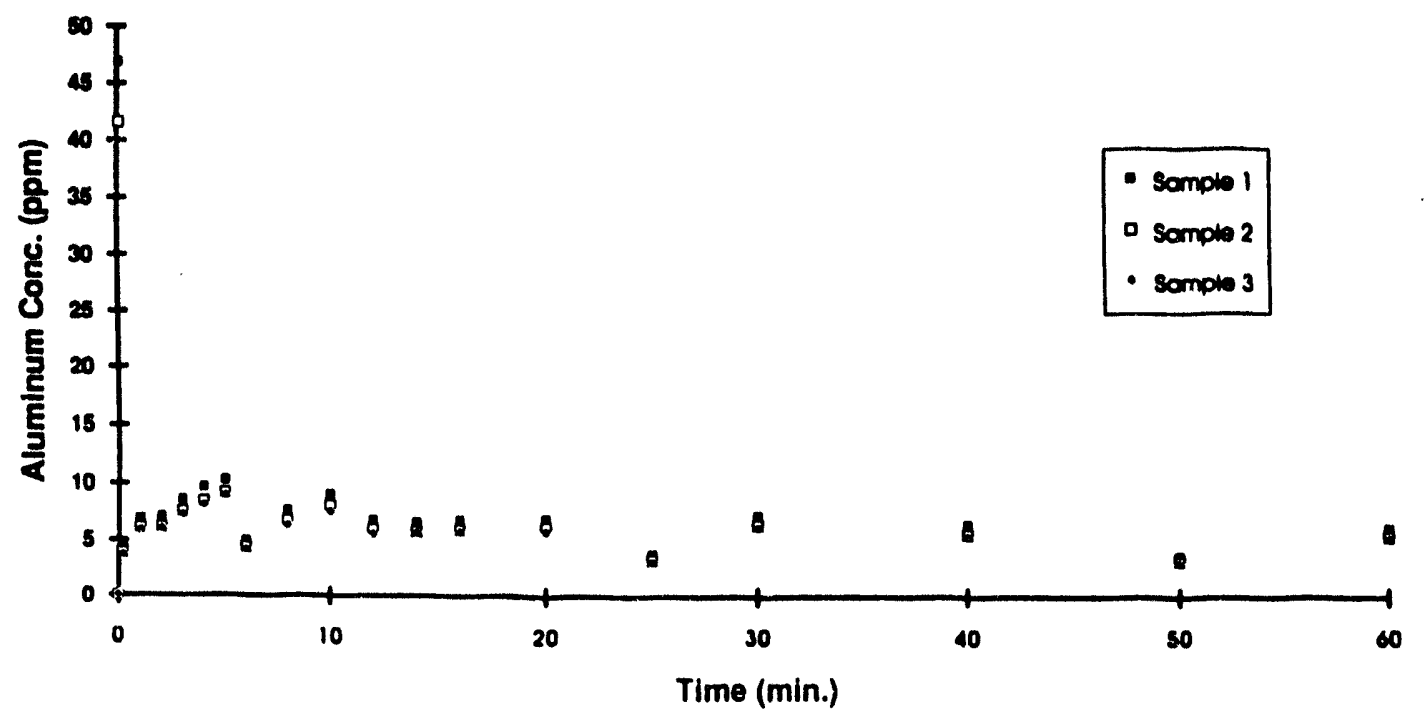

Figure 9. Raw Data for Multi-Element Kinetics Catalytic Effect of Copper on Aluminum (Aluminum Concentration)

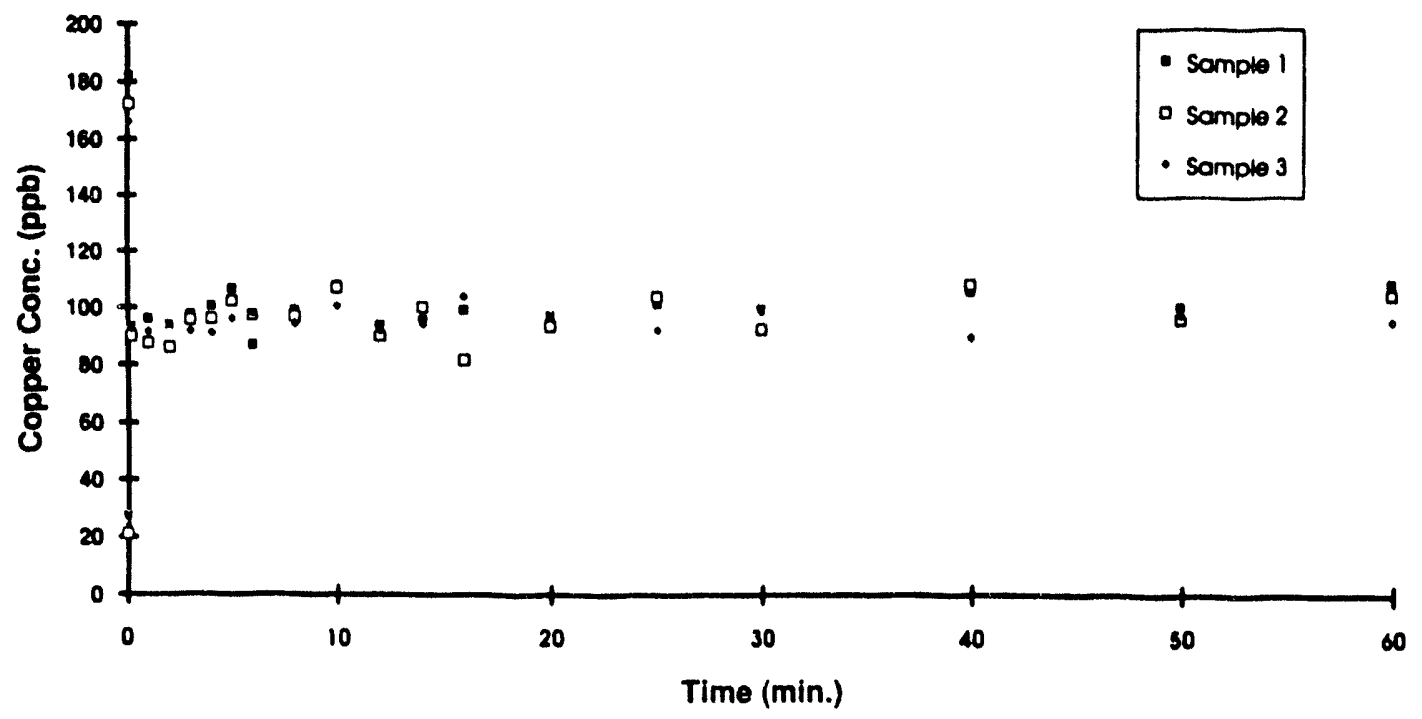

Figure 10. Raw Data for Multi-Element Kinetics Catalytic Effect of Copper on Aluminum (Copper Concentration) 


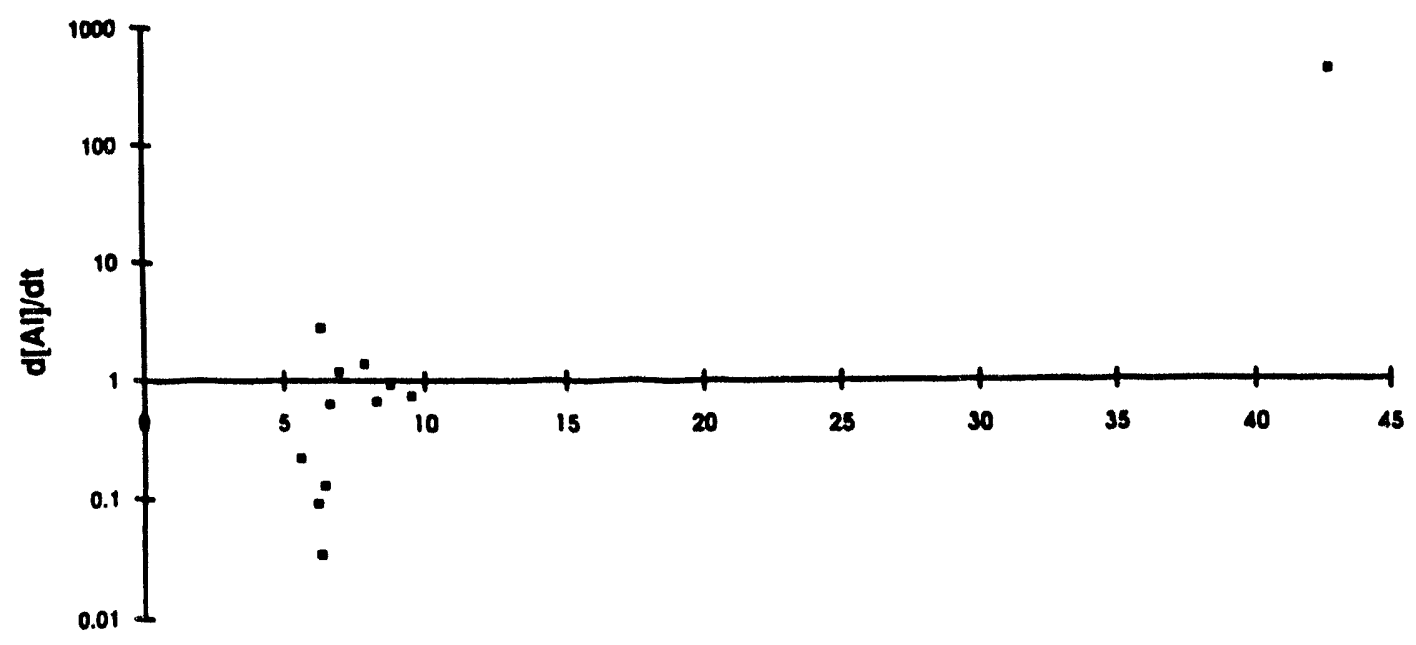

[AI]

Figure 11. Multi-Element Kinetics Modified Plot Determination of Aluminum Reaction Rate in the Presence of Copper

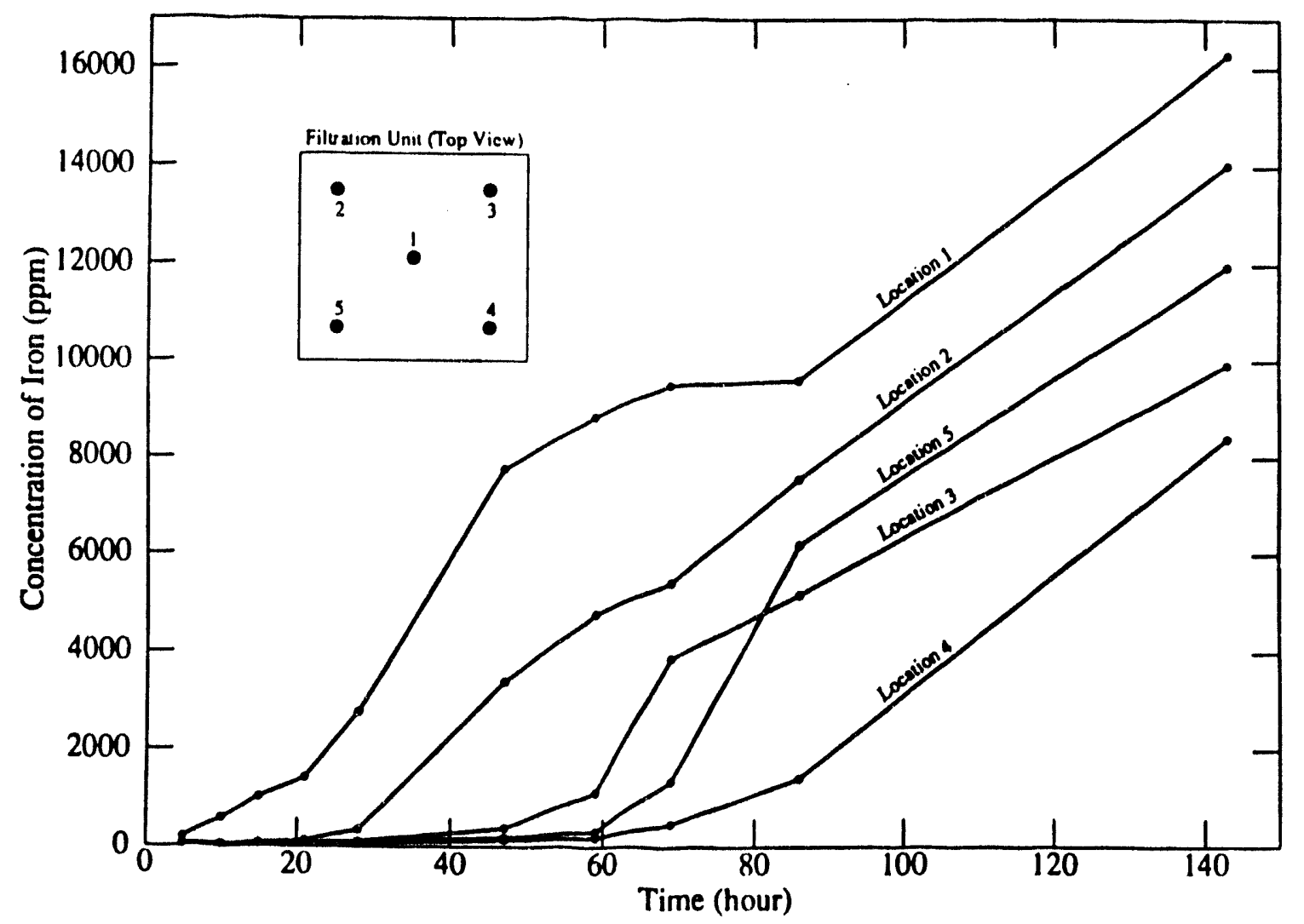

Figure 12. Contamination of Top Portion of Sand in Filtration Unit 


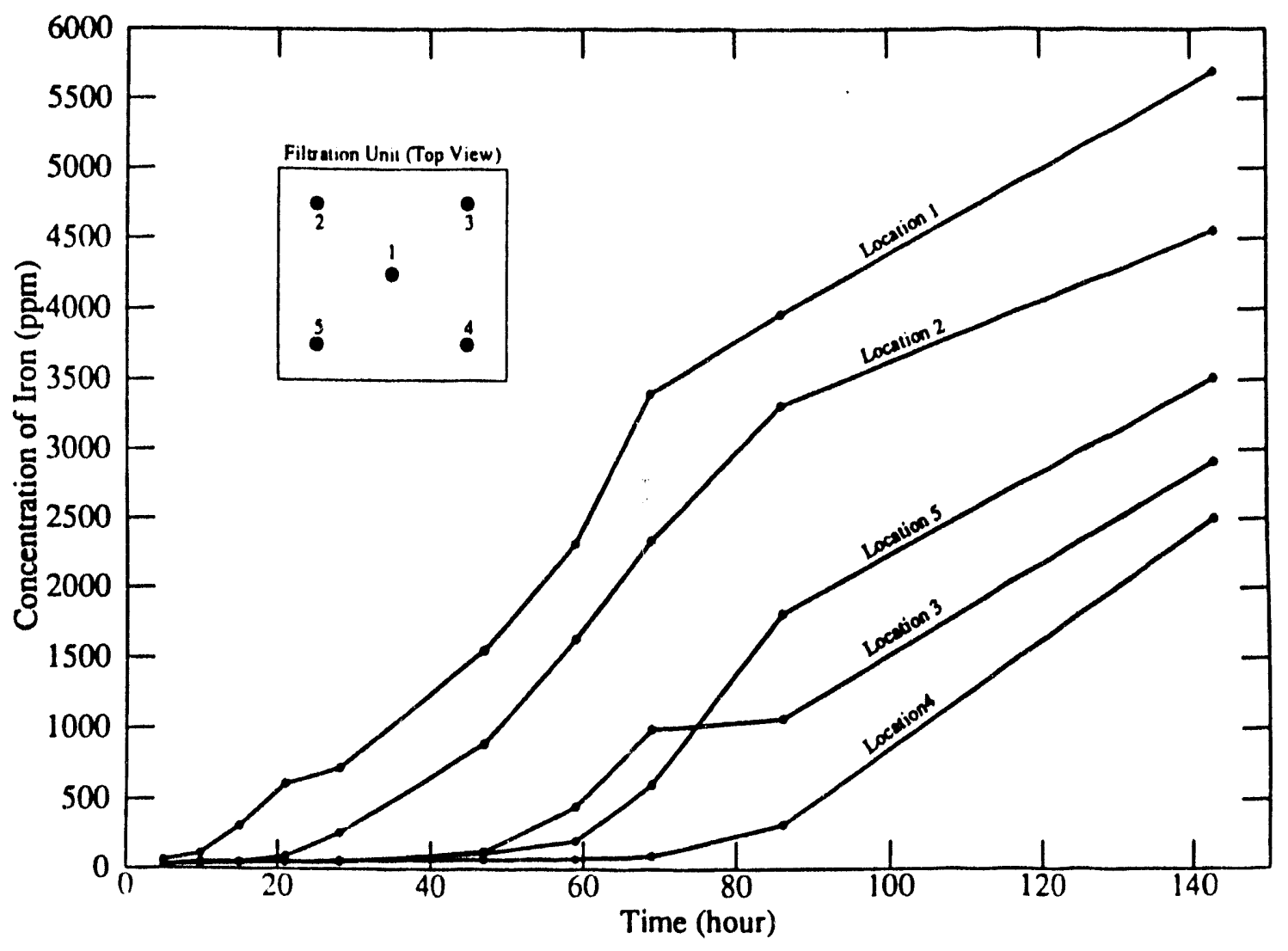

Figure 13. Contamination of Bottom Portion of Sand in Filtration Unit

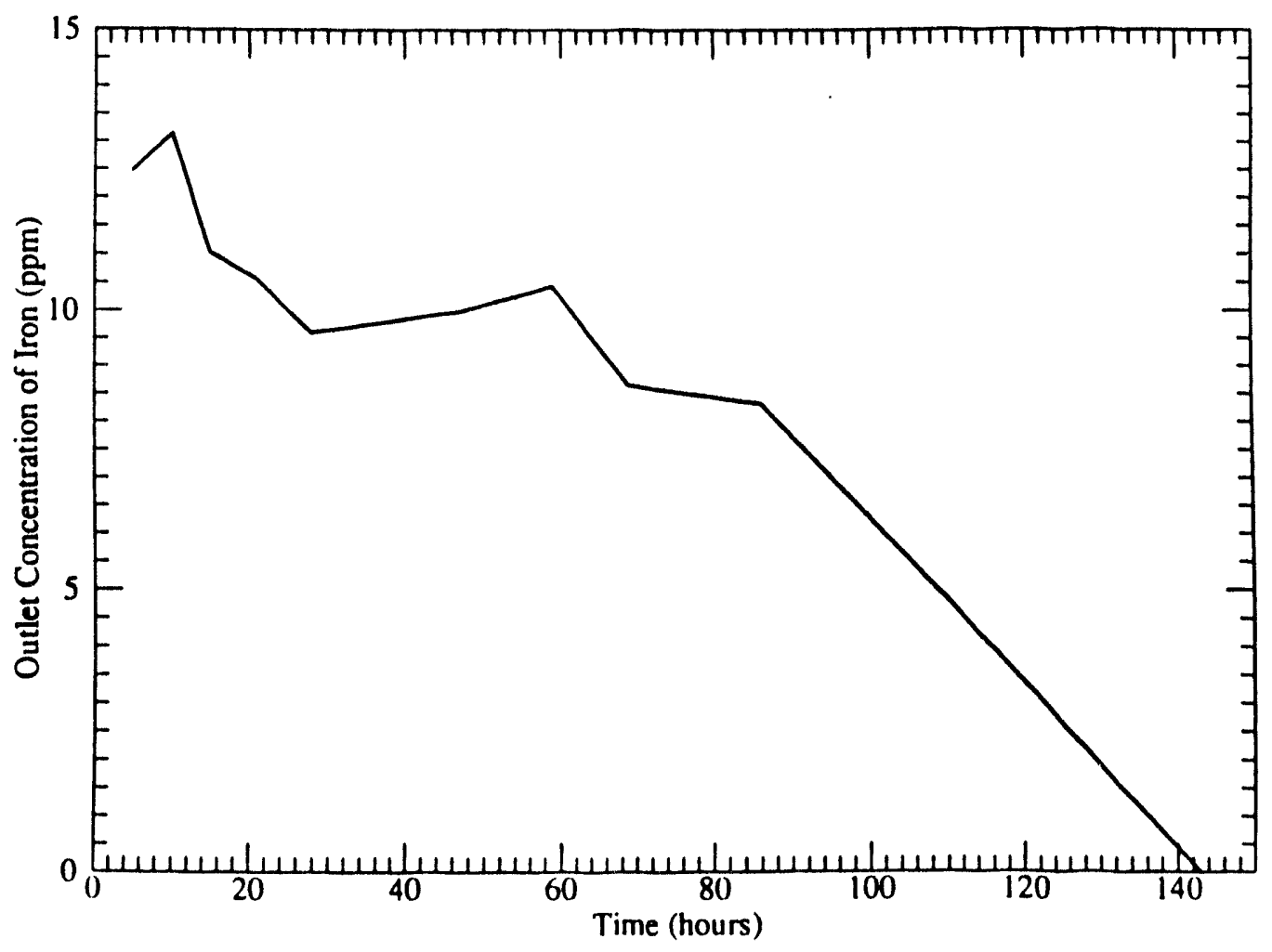

Figure 14. Outlet Iron Concentration vs. Time 


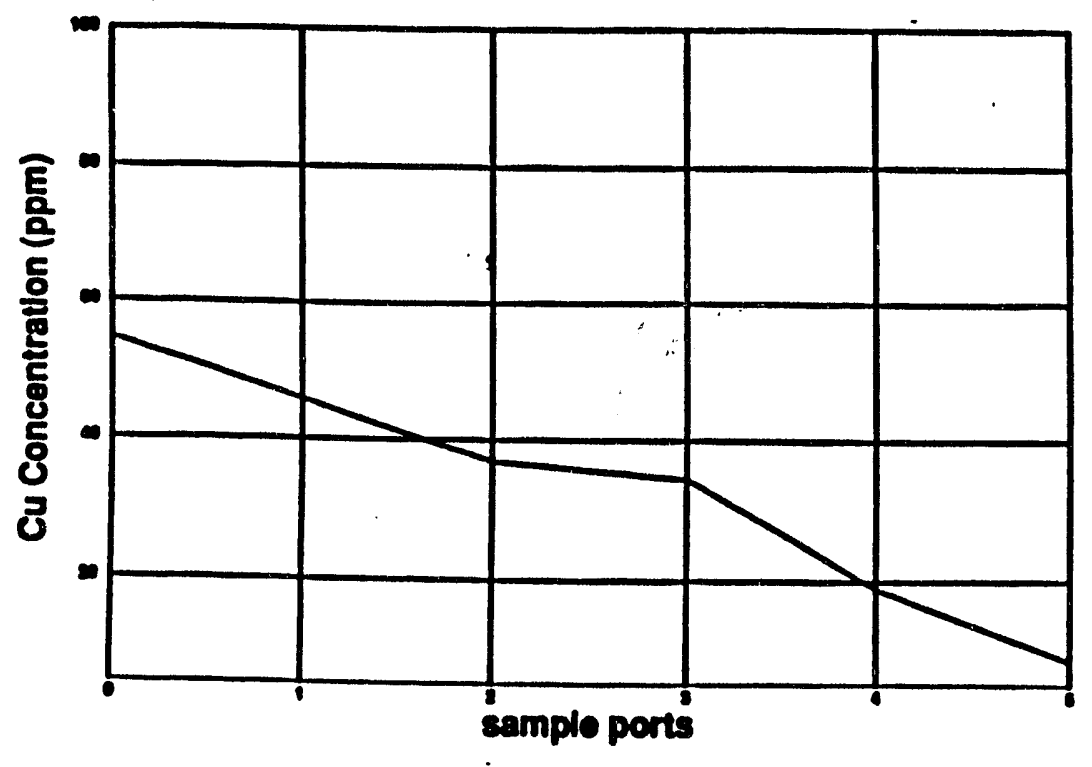

$0=$ Inlet

1= Exit $1=$ After First Limestone Column

2= Exit 2= After Second Limestone Column

$3=$ Exit $3=$ After Aeration Unit

4= Exit 4= After Solid Separator

$5=$ Exit $5=$ After Sand Filtration Unit

Figure 15. Average Copper Concentration throughout Laboratory Treatment Process Average Flow Rate: 2 bb/D; Aeration Unit Angle: $2^{\circ}$

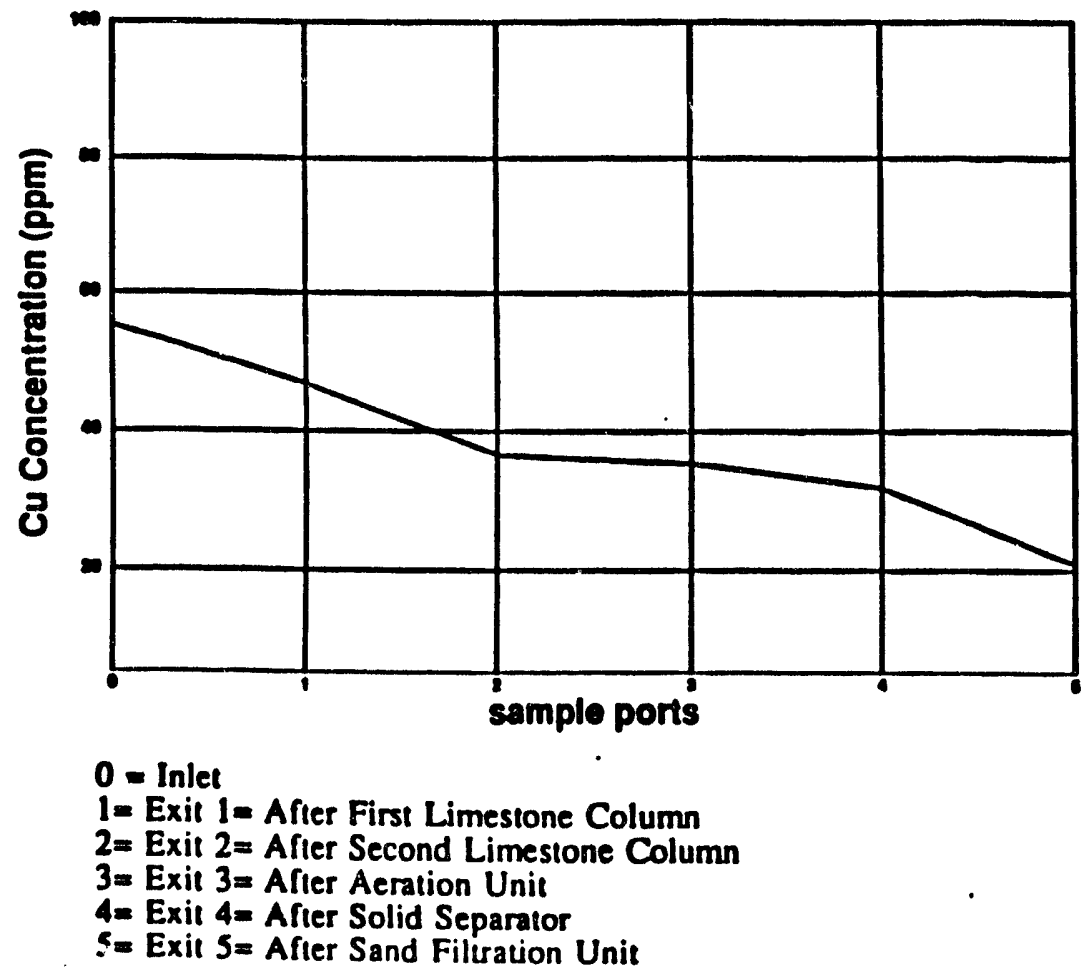

Figure 16. Average Copper Concentration throughout Laboratory Treatment Process Average Flow Rate: 4 bbl/D; Aeration Unit Angle: $2^{\circ}$ 


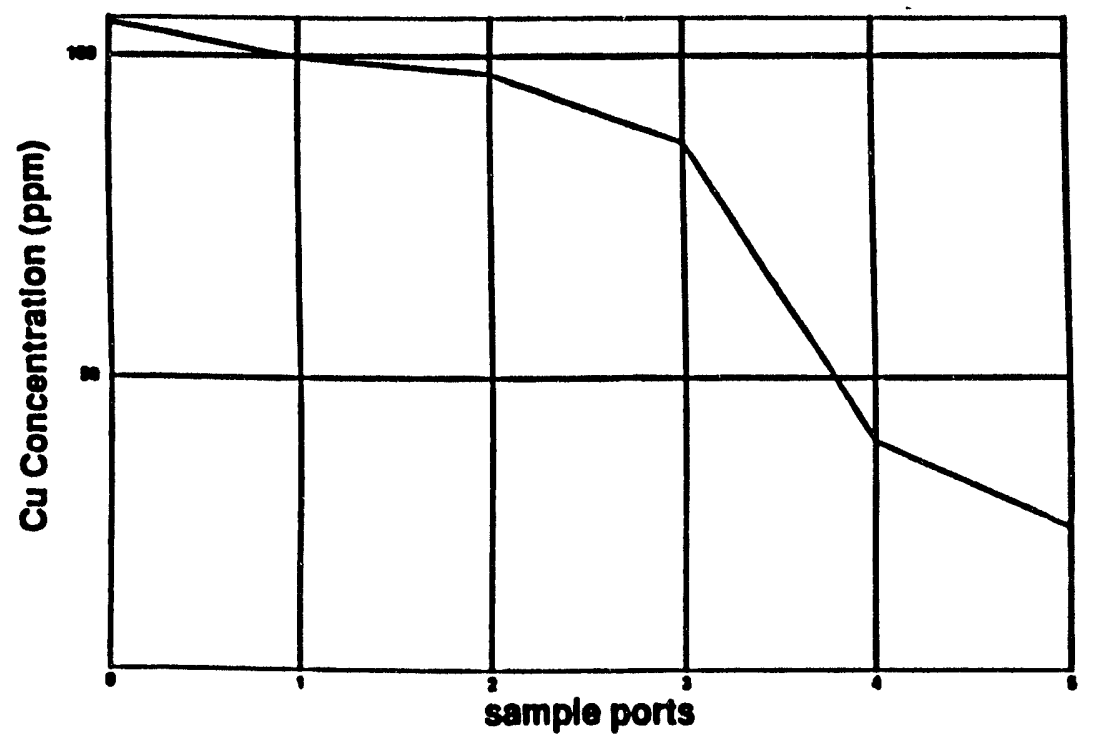

$\mathbf{0}=$ Inlet

$1=$ Exit $1=$ After First Limestone Column

2= Exit 2= After Second Limestone Column

3= Exit 3= After Aeration Unit

$4=$ Exit $4=$ Afier Solid Separator

$S=$ Exit $5=$ After Sand Filiration Unit

Figure 17. Average Copper Concentration throughout Laboratory Treatment Process Average Flow Rate: 2 bbl/D; Aeration Unit Angle: $15^{\circ}$

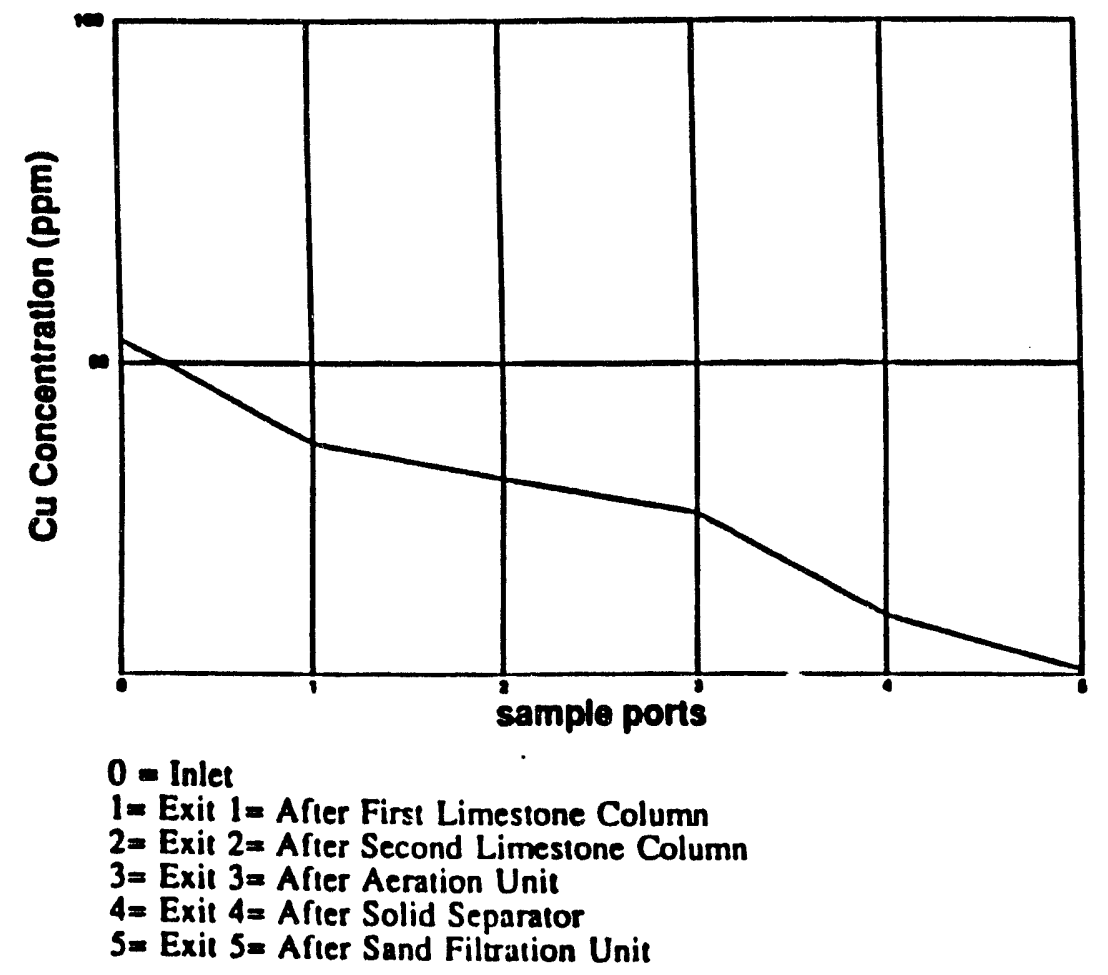

Figure 18. Average Copper Concentration throughout Laboratory Treatment Process Average Flow Rate: $2 \mathrm{bbl} / \mathrm{D}$; Aeration Unit Angle: $\mathbf{1 5}^{\circ}$ 


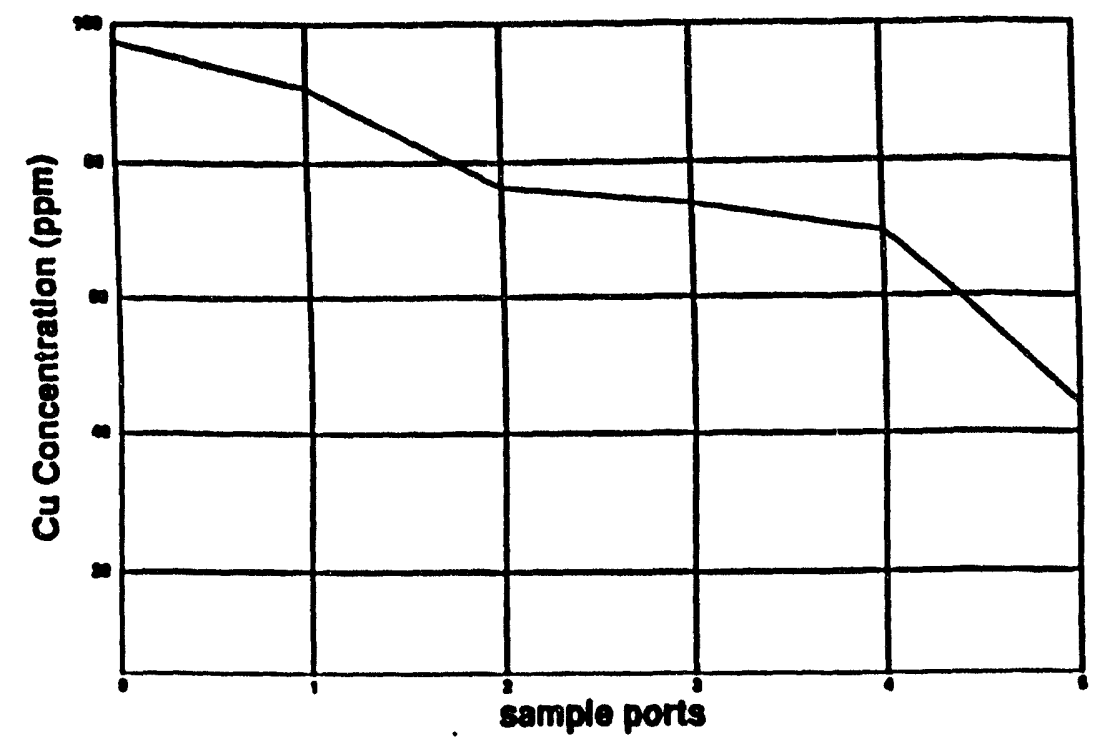

0 - Inlet

$1=$ Exit $1=$ After First Limestone Column

2= Exit 2= After Second Limestone Column

3= Exit 3= After Aeration Unit

$4=$ Exit $4=$ After Solid Separator

$S=$ Exit $S=$ After Sand Filtuation Unit

Figure 19. Average Copper Concentration throughout Laboratory Treatment Process Average Flow Rate: $4 \mathrm{bb} / \mathrm{D}$; Aeration Unit Angle: $2^{\circ}$

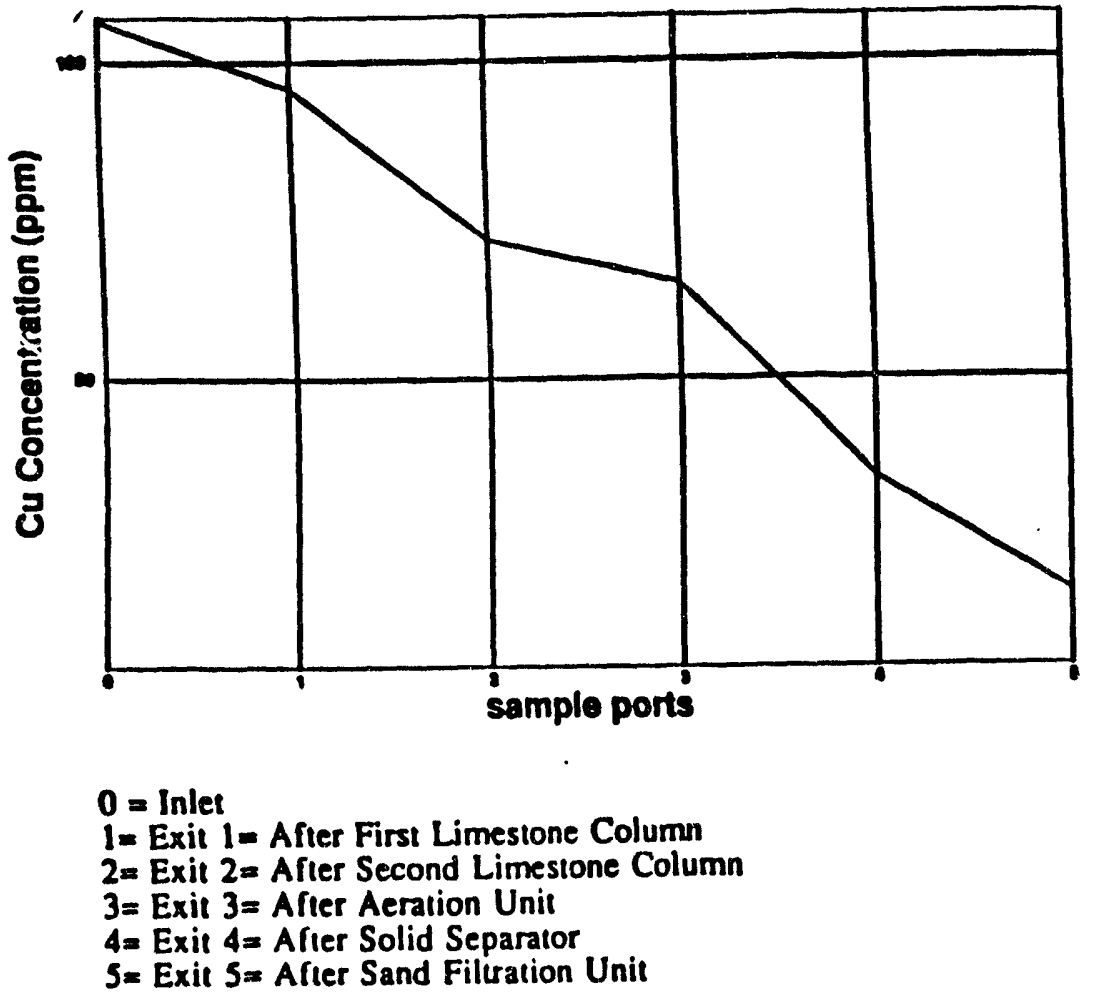

Figure 20. Average Copper Concentration throughout Laboratory Treatment Process Average Flow Rate: $2 \mathrm{bbl} / \mathrm{D}$; Aeration Unit Angle: $15^{\circ}$ 


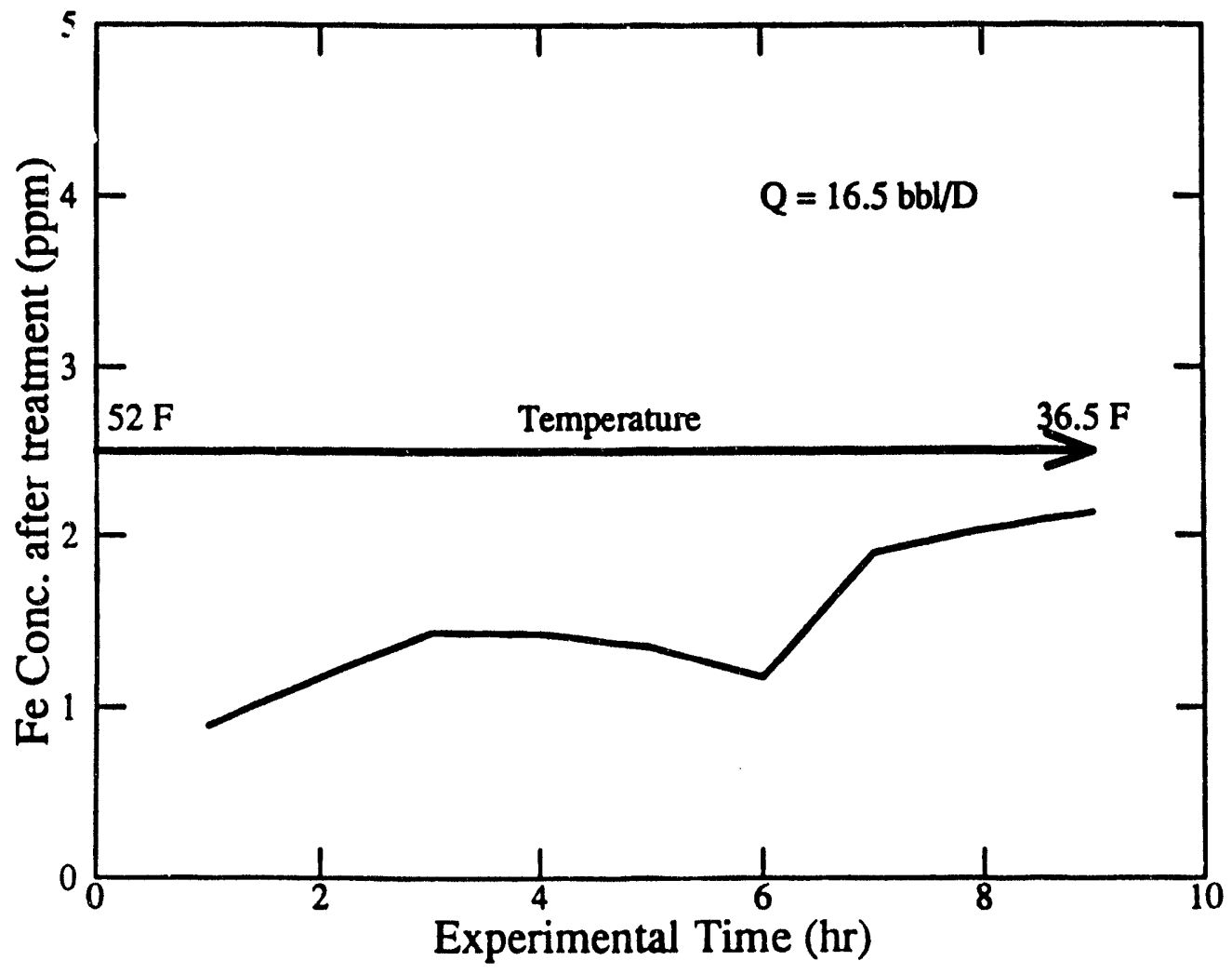

Figure 21. Effect of Temperature on Brine Treatment (Field Unit) 


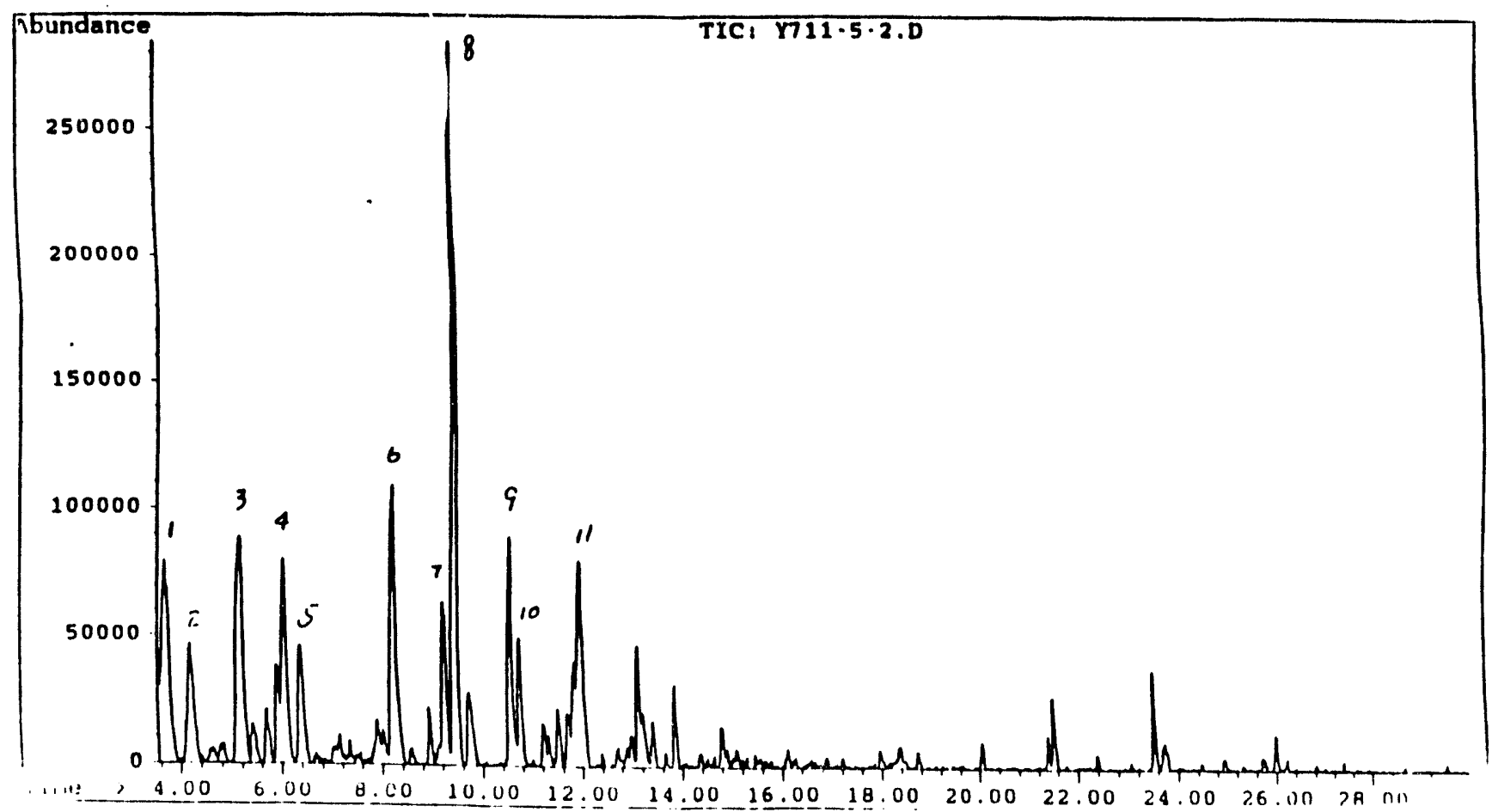

Figure 22. Chromatogram of Organics Analysis in Cooper Brine
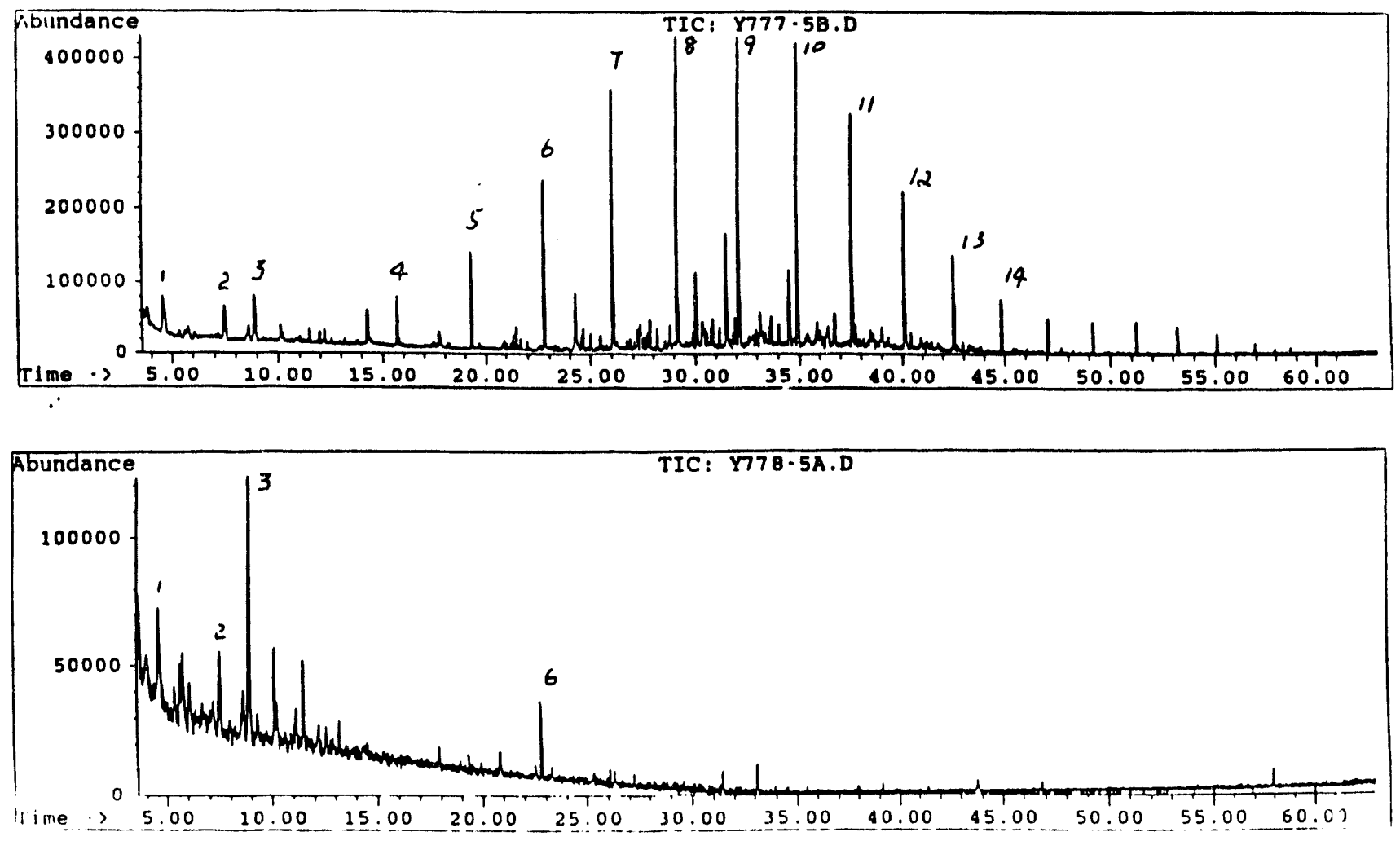

Figure 23. Chromatogram of Organics Analysis for Kane Brine 


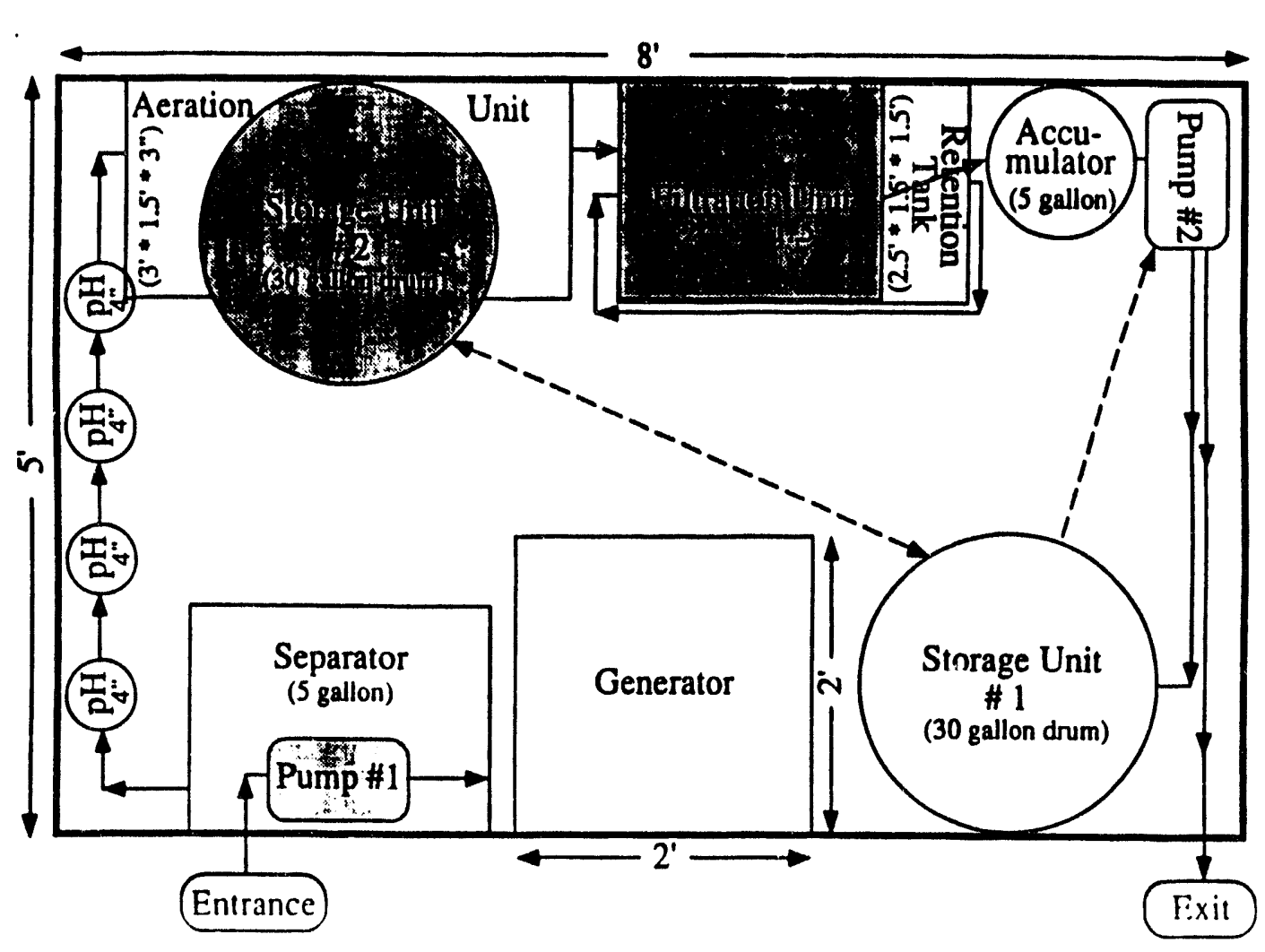

Figure 24. Schematic of Mobile Brine Treatment Facility

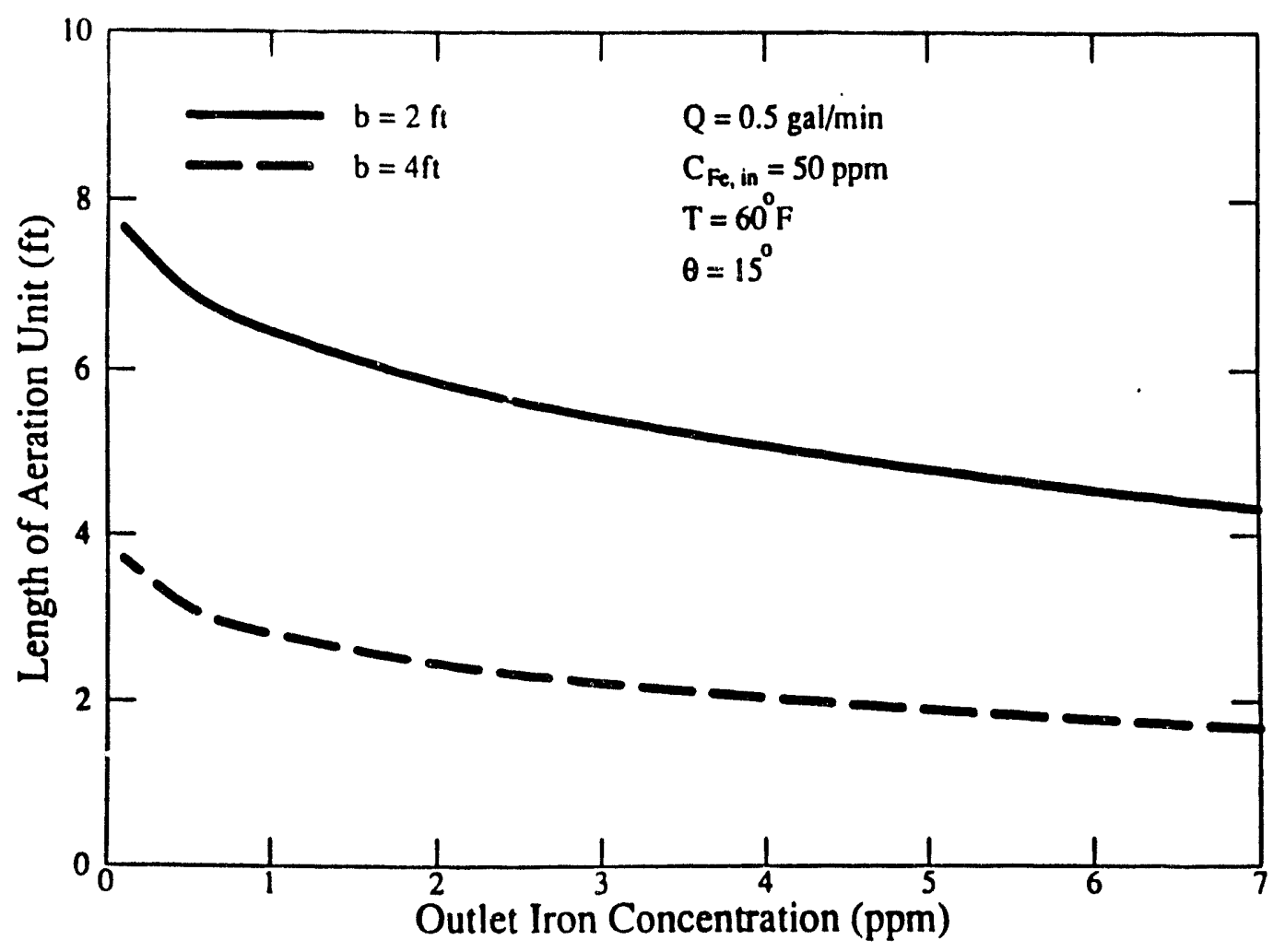

Figure 25. Example of Designing Length of Aeration Unit 


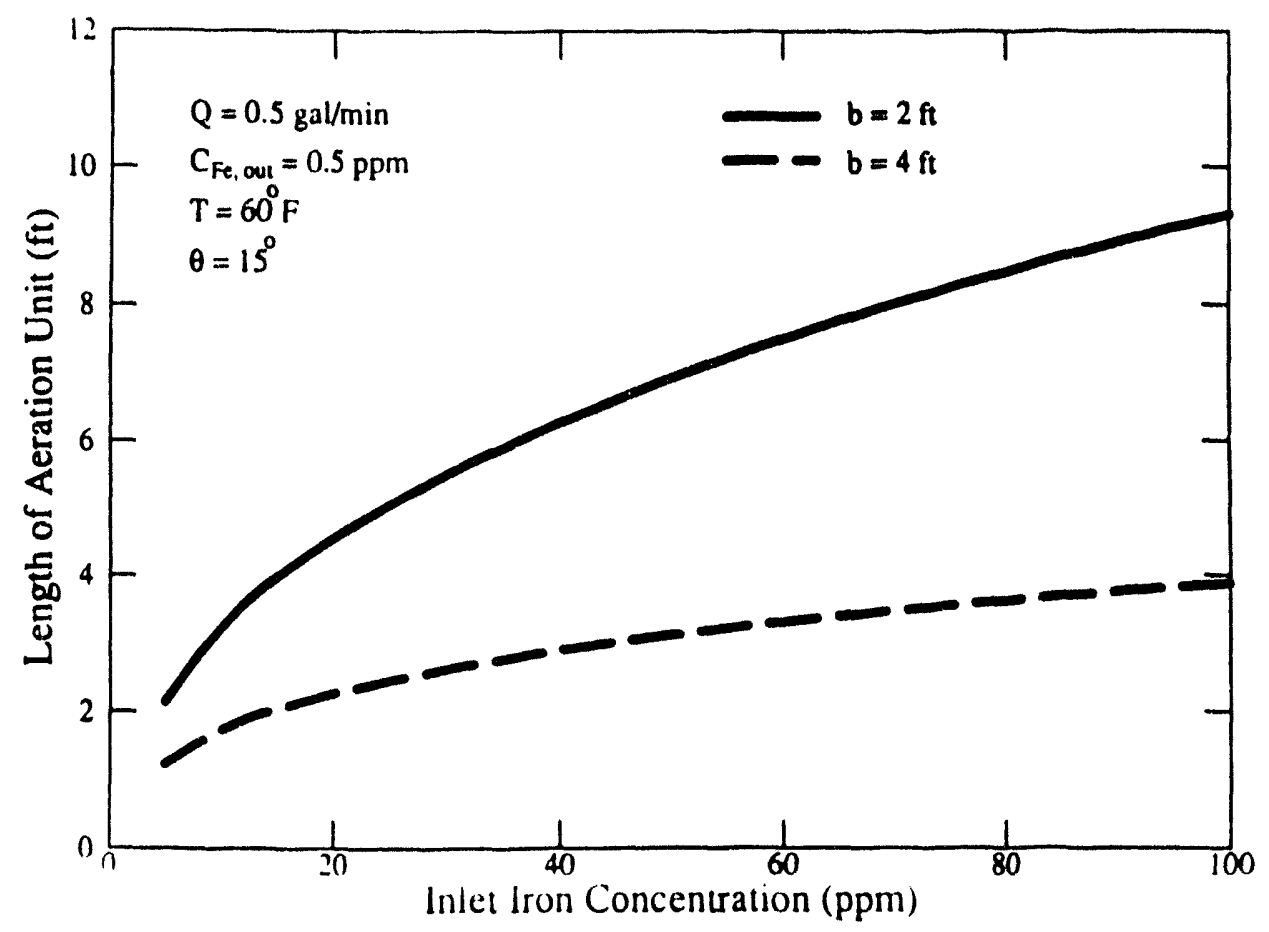

Figure 26. Example of Designing Length of Aeration Unit

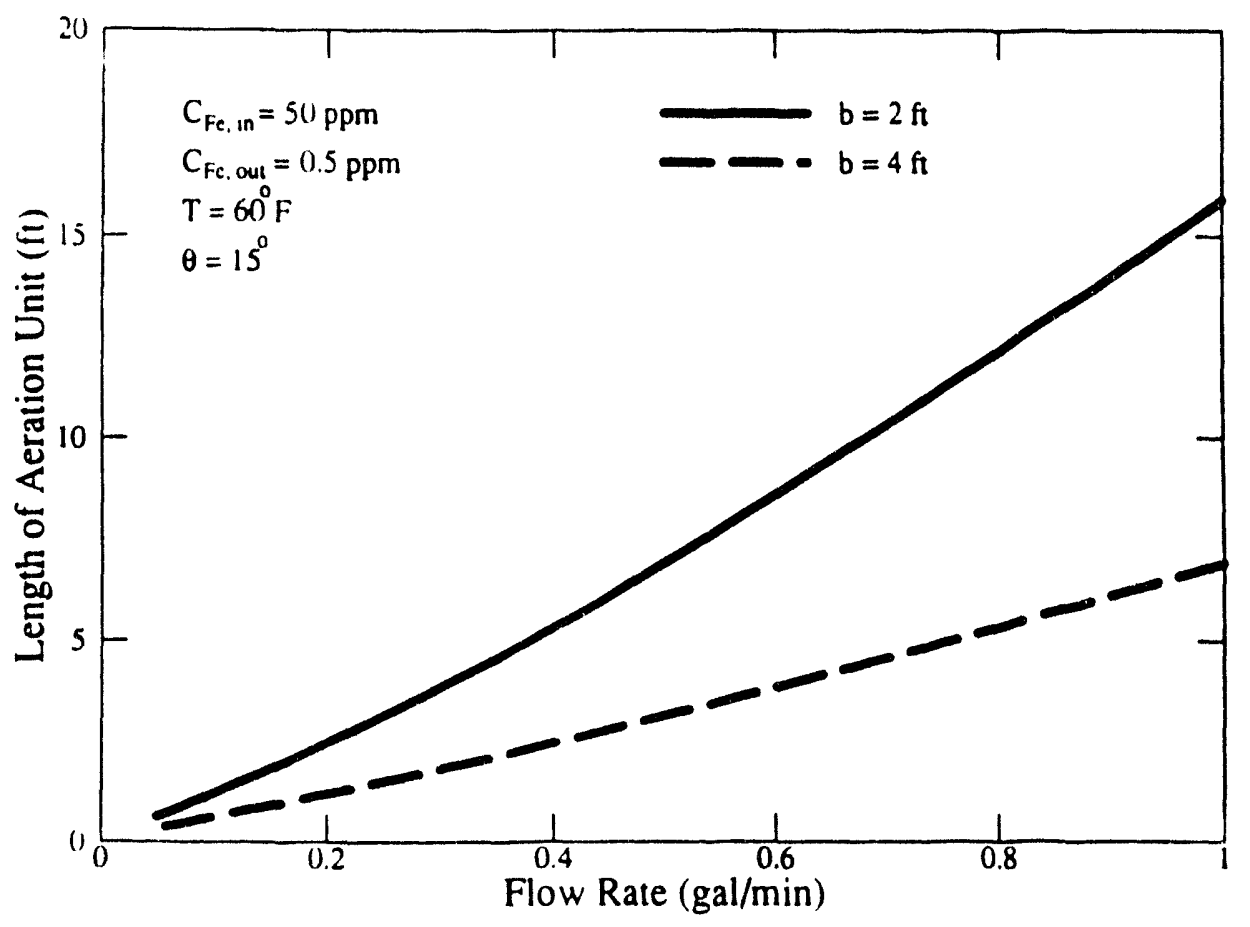

Figure 27. Example of Designing Length of Aeration Unit 


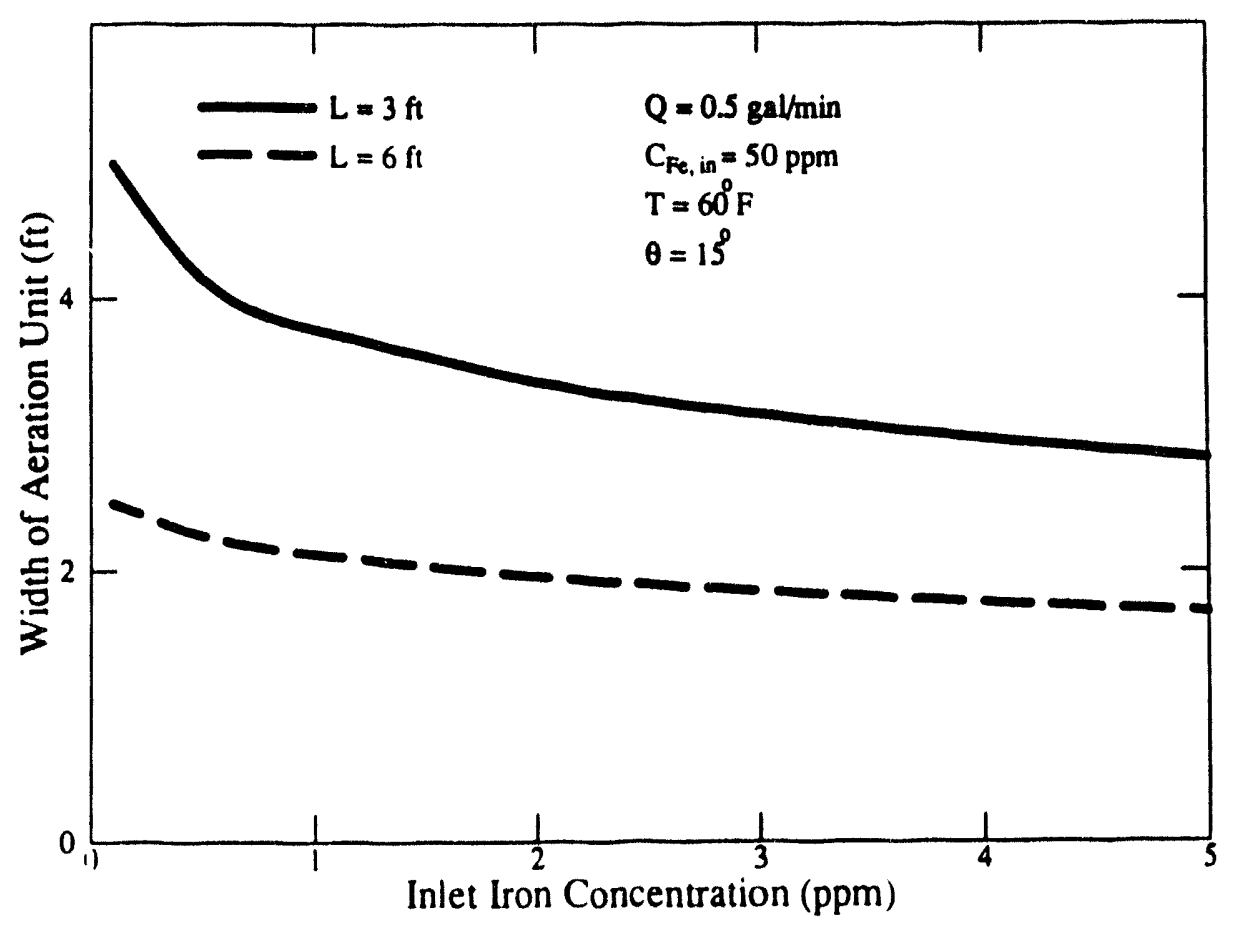

Figure 28. Example of Designing Width of Aeration Unit

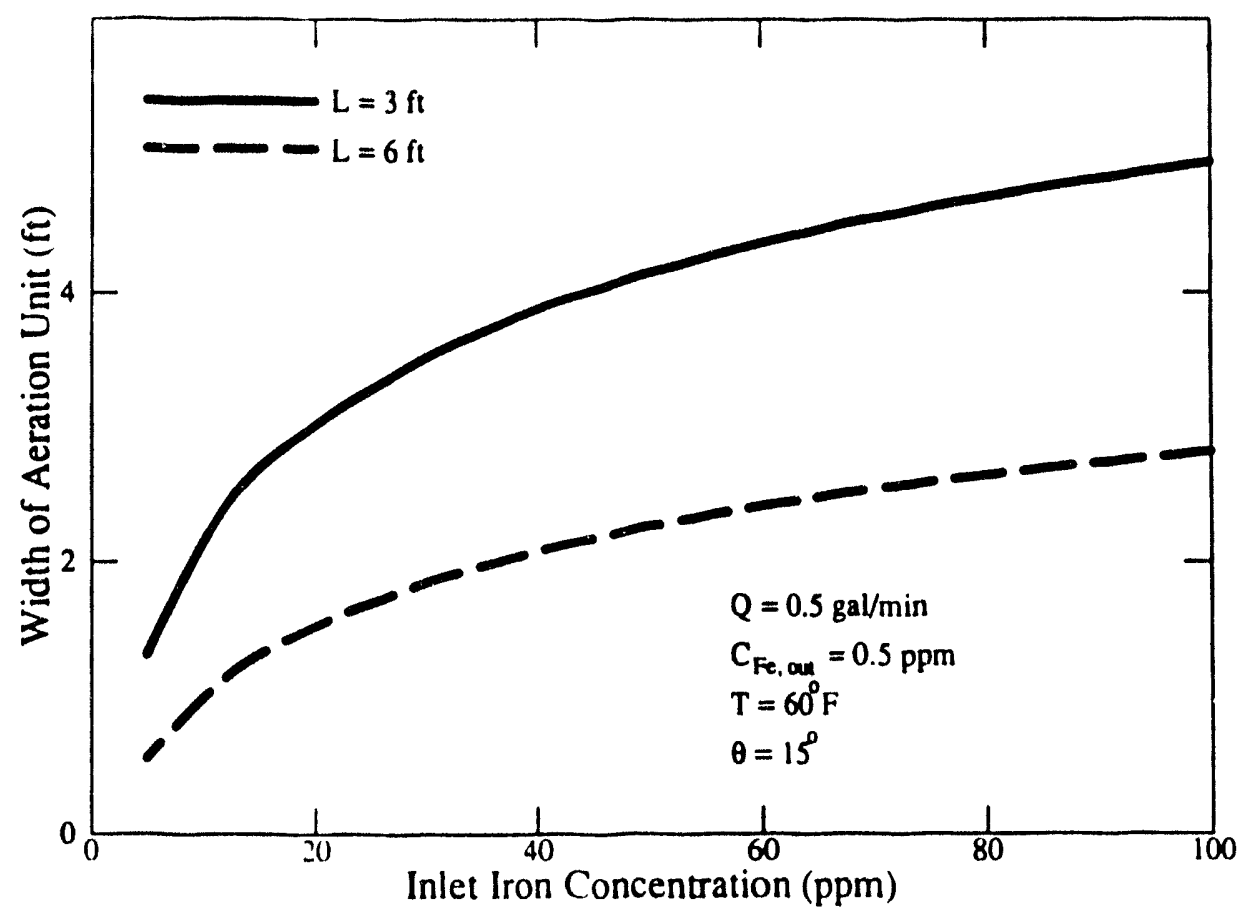

Figure 29. Example of Designing Width of Aeration Unit 


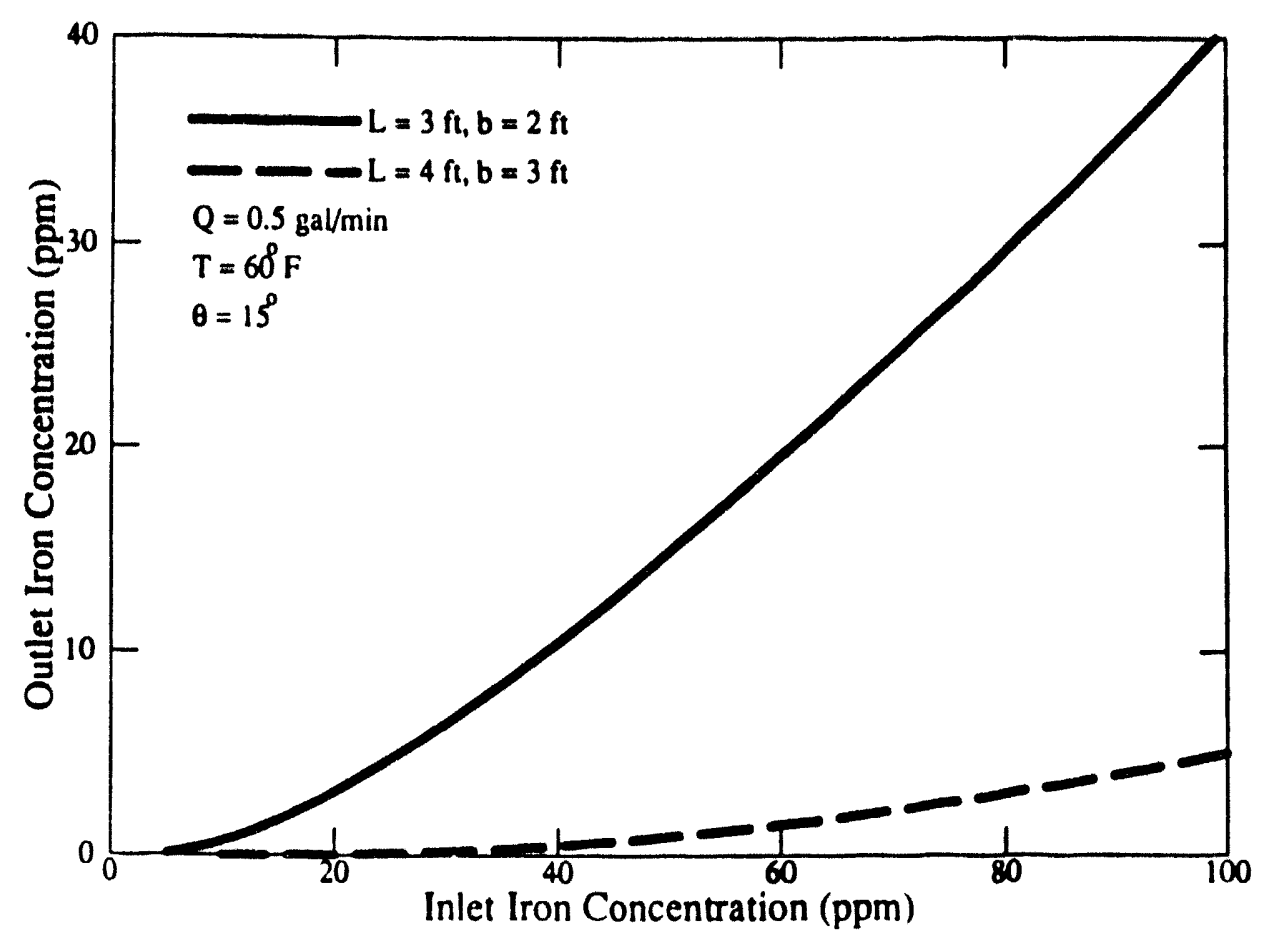

Figure 30. Example of Predicting Outlet Iron Concentration

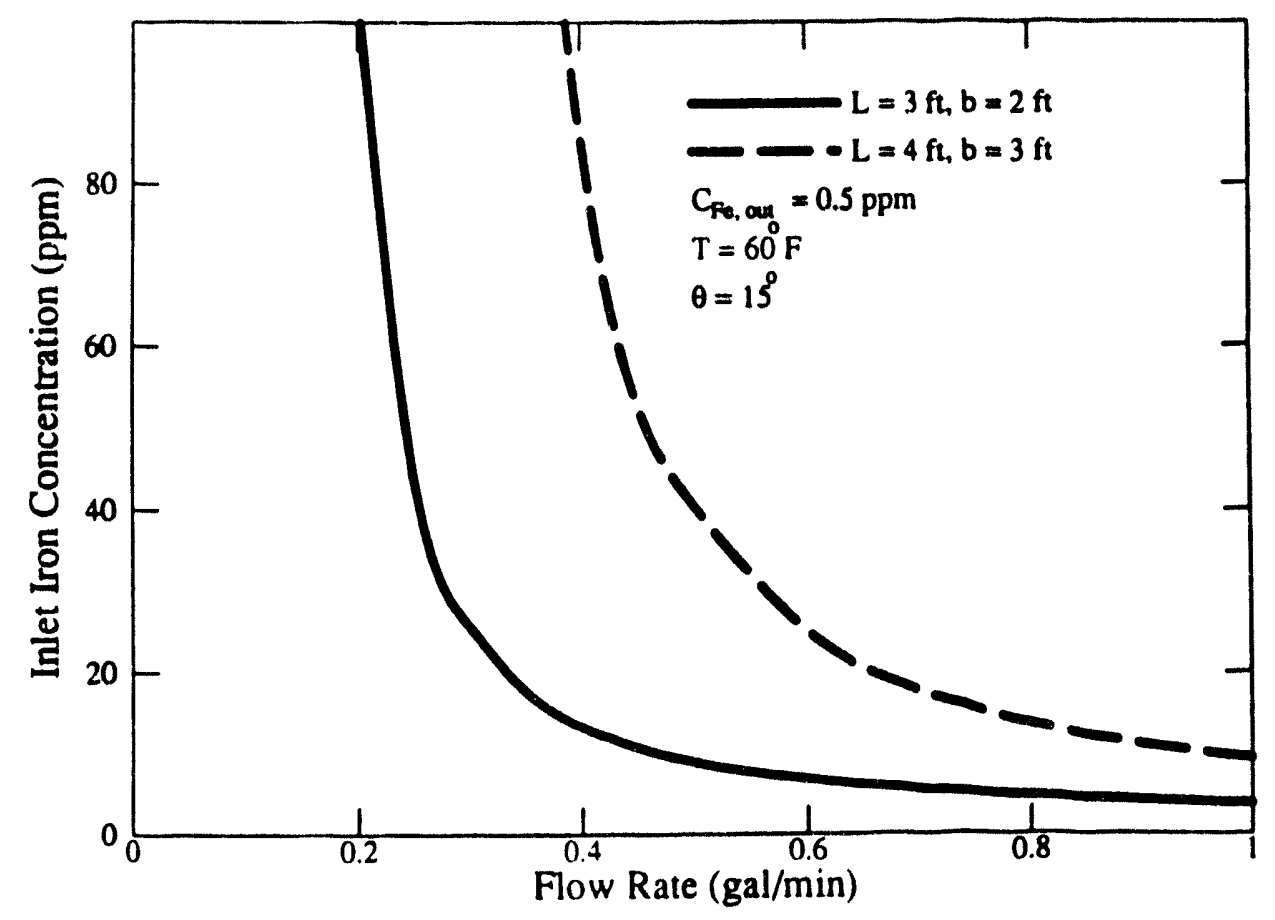

Figure 31. Example of Determining Maximum Inlet Iron Concentration 


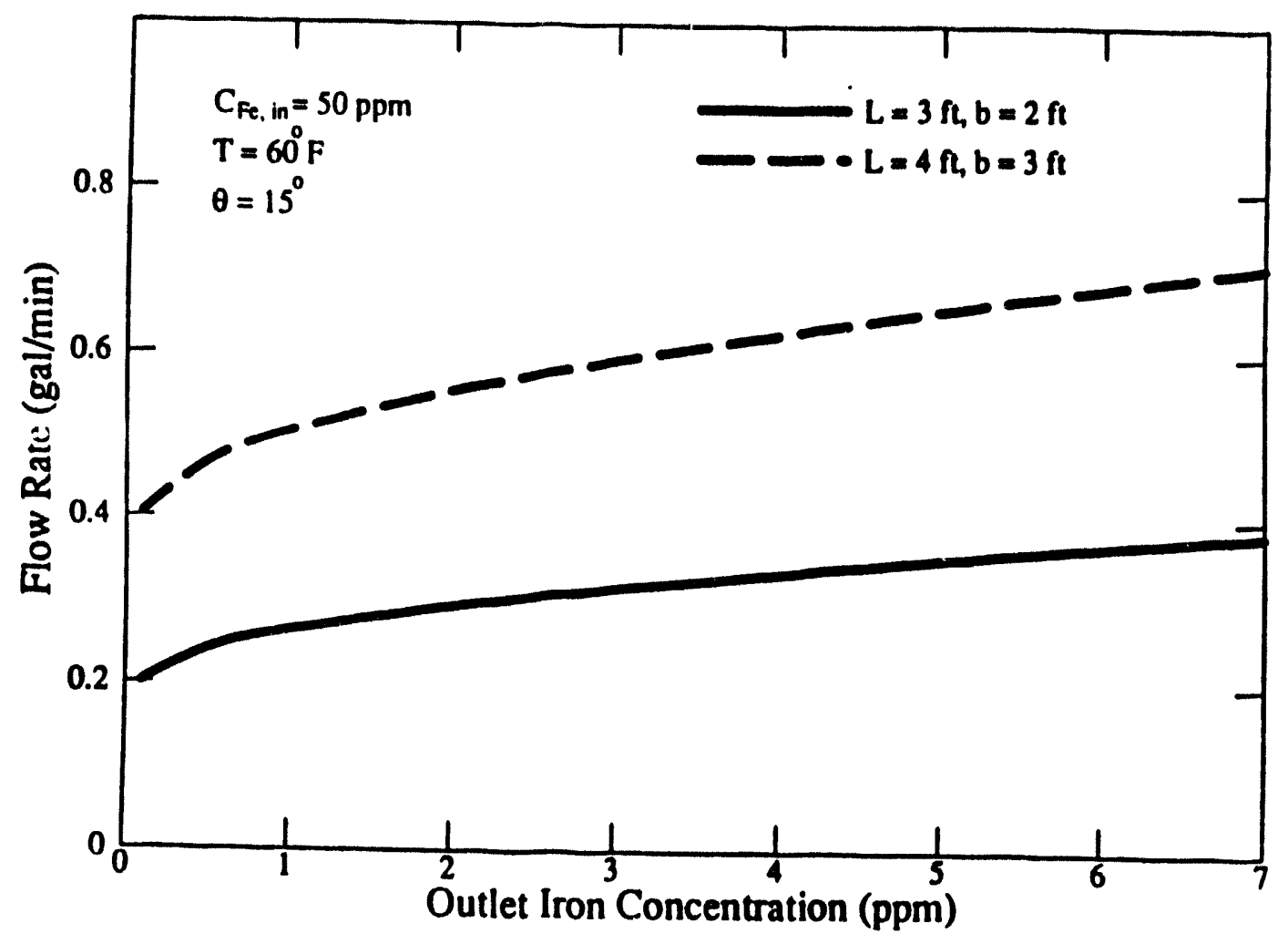

Figure 32. Example of Determining Maximum Flow Rate 

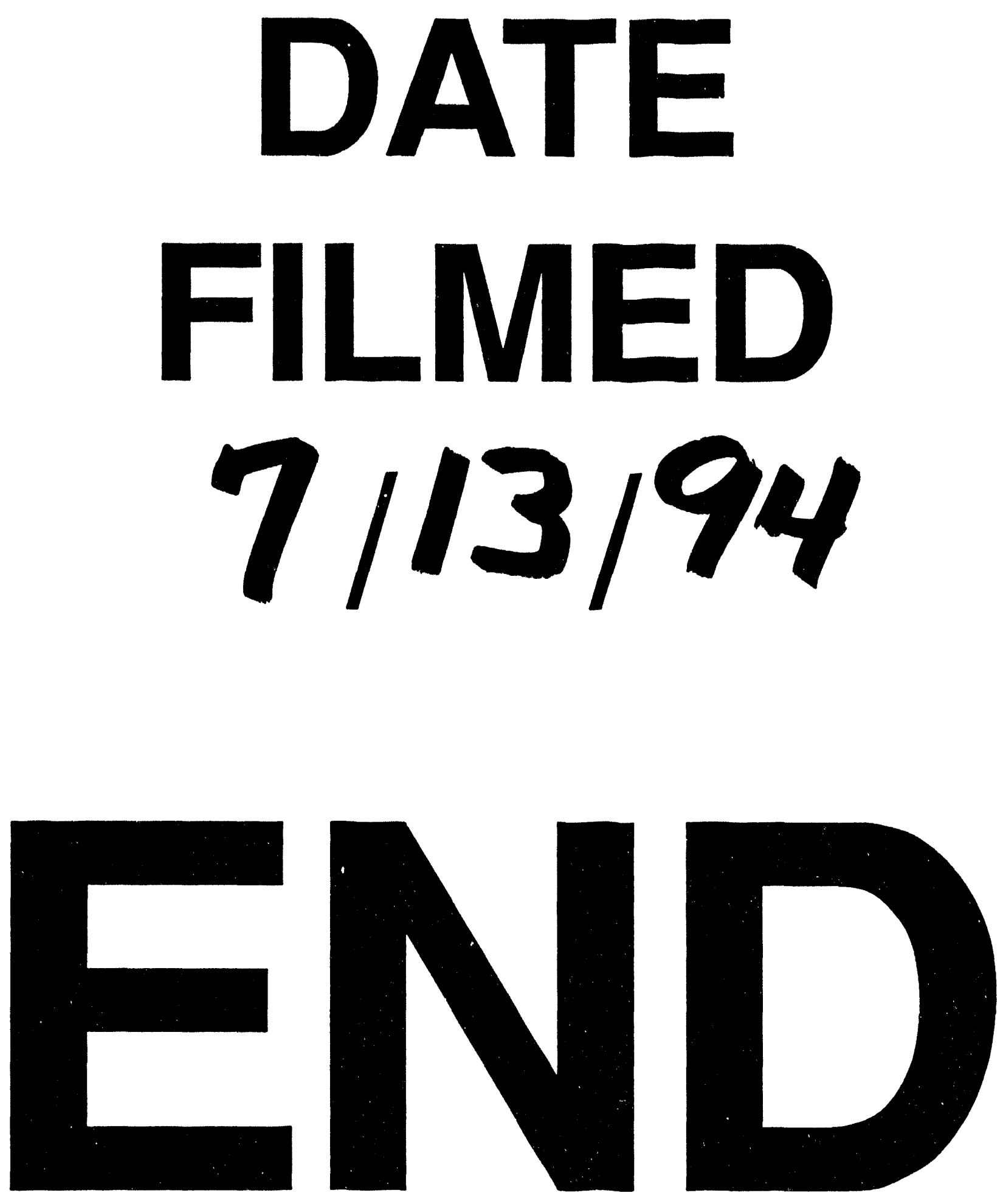


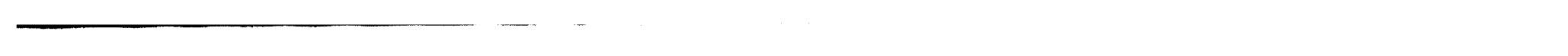

$\overline{-}-$

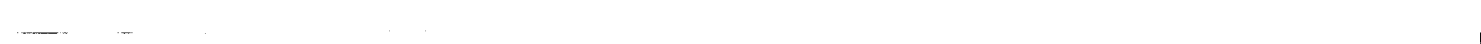

